\title{
Development of multifunctional coatings for protecting stones and lime mortars of the Architectural Heritage
}

\author{
A. Speziale ${ }^{1}$, J.F. González-Sánchez ${ }^{1}$, B. Taşci ${ }^{1}$, A. Pastor ${ }^{2}$, L. Sánchez ${ }^{2}$, C. Fernández \\ Acevedo $^{3}$, T. Oroz Mateo ${ }^{3}$, C. Salazar ${ }^{3}$, I. Navarro-Blasco ${ }^{1}$, J.M. Fernández ${ }^{1 *}$, J.I. Alvarez ${ }^{1}$ \\ (1) MATCH group, Department of Chemistry, University of Navarra, Pamplona, Spain \\ (2) Department of Inorganic Chemistry, University of Córdoba, Córdoba, Spain \\ (3) Lurederra Technological Centre, Lurederra Technological Centre, Los Arcos, Spain
}

Published in International Journal of Architectural Heritage, 2020, in the special issue devoted to papers presented at the 5th Historic Mortars Conference, HMC 2019, held at the University of Navarra, 19-21 June 2019. Appeared online on 2020-03-04.

\section{https://dx.doi.org/10.1080/15583058.2020.1728594}

\section{Abstract}

Unique multifunctional coatings, comprising a 3D superhydrophobic agent and two nanostructured photocatalysts (solar-light sensitive 50/50 and 10/90 $\mathrm{TiO}_{2}-\mathrm{ZnO}$ nanoheterostructures), compatible with the inorganic substrates of the Built Heritage, have been designed.

The synthesized nanoparticles showed an enhanced photocatalytic activity (tested by $\mathrm{NO}$ degradation) as compared with the raw $\mathrm{TiO}_{2}$ and $\mathrm{ZnO}$ materials.

Dispersing agents were used to optimize the coatings, avoiding agglomeration of the photocatalytic nanoparticles and increasing the stability of the suspensions. Four distinct dispersions were optimized and applied as coatings onto stony materials used in the Built Heritage, such as sandstone, lime mortar, granite and limestone. Their effectiveness was assessed by assessing hydrophobicity of the surfaces (static water contact angle), photocatalytic activity and self-cleaning as well as water vapour permeability of the treated specimens. These transparent coatings demonstrated high compatibility with the construction materials of the Architectural Heritage and showed a synergistic effect rendering a minimized water absorption, self-cleaning ability evidenced by the reduced adsorption of soiling deposits and a reasonable degradation of any trace that might be adsorbed, as well as a protecting hydrophobic environment for the photocatalyst.

\section{Introduction}

Built Heritage is subjected to deterioration caused by a number of factors, environmental and anthropogenic as well. Among the first type, blackening of surfaces due to carbon particles accumulation, nitrogen oxides action and bacteria-induced 
growing of microorganisms may be cited (Brimblecombe and Grossi, 2005; Gulotta et al. 2018; Pozo-Antonio et al. 2019; Vidal et al. 2019)

The water access to the inner part of the building materials might be commented as another way of deterioration (Brai et al., 2007; Piuzzi et al. 2018). As a matter of fact, water can penetrate into the materials giving rise to soluble salts dissolution, efflorescences and the breaking of the materials due to freezing-thawing cycles. Among the factors due to the direct human intervention, graffiti can be mentioned as a paradigmatic example (Sanmartín et al. 2014; Gomes et al. 2018). These damaging factors are detrimental for the Cultural Heritage preservation, which demands large reparation endeavours and funds. These adverse circumstances can be dealt with, and mitigated to a certain extent, by appropriate treatments of the surfaces of the building materials and/or of the repair materials after their in situ application.

So far, scientific literature and technological knowledge has provided suitable approaches to this end comprising, on one hand, the individual use of water repellents to hinder the access of water (Toniolo et al. 2002; Manoudis et al. 2009; Fermo et al. 2014) and, on the other hand, the obtaining of "smart" surfaces, by applying photocatalytic agents (with biocide ability), responsible for the degradation of dirt and for the reduction of the biological growth, because the photocatalytic cleavage of bonds between microorganisms and substrates (Wolfrum et al. 2002; Licciulli et al. 2011; Kapridaki and Maravelaki-Kalaitzaki 2013; Kapridaki et al. 2014; Bergamonti et al. 2015).

Different strategies of achieving water repellency have been proposed and discussed (Tserepi, Vlachopoulou and Gogolides 2006; Manoudis et al. 2009). Most of them are based on the application of organic compounds: resins, acrylate-based compounds, waxes ... (Alessandrini et al. 2000; Toniolo et al. 2002; Fermo et al. 2014; Andreotti et al. 2018; Aslanidou, Karapanagiotis and Lampakis 2018; Winandy, Schlebusch and Fischer 2019). Different anti-graffiti treatments depending on the easiness of their removal after several cleaning processes have been tested by Macchia et al. (2019). Besides the limited durability of some of these treatments, other drawbacks can be associated to these coatings (Turk et al. 2019): i) high viscosity, colour and gloss changes leading to a thick, coloured coating (Liu and Zhang, 2007); ii) formulation based on organic compounds, with inadequate compatibility with the ancient building materials and some of them with toxicity upon removal from the substrate (Melo et al. 1999; and, finally, iii) excessive and thus unsuitable reduction of water vapour permeability, which would result in a detrimental water accumulation inside the building materials (Doehne and Price, 2010).

Photocatalysts have been also applied on surfaces of building materials as active coatings (Nath et al. 2013; Hot et al. 2017; Yang et al. 2018; Veltri et al. 2019). Photocatalytic oxidation of dirt compounds by $\mathrm{TiO}_{2}$ is widely known but its 
effectiveness is confined under UV radiation (Khan et al. 2014; Khalid et al. 2017). This fact restricts the activity of the titania to be activated by just $4.5 \%$ of UV photons of the solar irradiation. In addition, during the coating application, the agglomeration of the particles results in a reduction of the number of active sites of the photocatalyst and in a fast electron-hole recombination due to the proximity of the photocatalytic particles (Zhu et al. 2013; Pérez-Nicolás et al. 2018; Guo et al. 2019; Zhu and Zhou 2019). These factors lead to an efficiency drop. Two strategies to overcome these problems could be set up: i) the obtaining of photocatalyst which action may be extended to the visible radiation increasing its sensitivity range and thus its efficiency (Du et al. 2019; Mas et al. 2020); ii) the use of compatible dispersing agents, which could be beneficial to guarantee a good distribution of the photocatalyst all over the surface (Pérez-Nicolás et al. 2018 ).

Bearing in mind these possibilities and the restrictions of these materials, this research work intends to explore the efficiency of a multifunctional coating, in which a compatible superhydrophobic agent and photocatalysts have been combined simultaneously. Compatibility appears as an essential requirement, since photocatalysts based on $\mathrm{TiO}_{2}$ evidence intrinsic hydrophilicity (photo-induced superhydrophilicity under light radiation) and thus might act in an opposite way to that of the hydrophobic agent (Wang et al. 2017). A synergistic action could be reasonably expected, in which the superhydrophobic compound minimizes the adsorption of soiling deposits, whereas the photocatalyst degrades any trace of these adsorbed products. Moreover, a hydrophobic environment could protect the photocatalyst from washing away owing to the rain action (Shajari-Ghasemkheili and Sarraf-Mamoory 2019). In support of this approach, the scientific literature provides some works dealing with photocatalytic-hydrophobic coatings (Kamegawa, Shimizu and Yamashita 2012; La Russa et al. 2012; Kapridaki and Maravelaki-Kalaitzaki 2013; Kapridaki et al. 2014; Gobakis et al. 2015; Kamegawa, Irikawa and Yamashita 2015; Kapridaki and Maravelaki 2016; Aldoasri et al. 2017; Colangiuli et al. 2019; Lanka et al. 2019; ShajariGhasemkheili and Sarraf-Mamoory 2019. However, the coatings so far reported for Built Heritage are based on $\mathrm{TiO}_{2}$ and organic water repellent agents.

The novelty of this work is supported in the obtaining of multifunctional coatings by the generation of a 3D structure integrating the active nanoparticles. The water repellent 3D structure includes ceramic nano-oxides, and its essentially inorganic composition, thus increasing the compatibility with the inorganic substrates of the Built Heritage and minimizing the use of organic compounds. This 3D structure was formed as a consequence of the assembly of the 1D nanomaterials into threedimensional (3D) superstructures of higher order such as nanoarrays, nanoforests, and networks (Lau et al. 2003; Meseck et al. 2014). Furthermore, the small cavities of the matrix enable the breathability of the coating. In this way, the water vapor is not accumulated in the treated masonry, and protection is achieved without sealing. The 
active nanoparticles of the photocatalyst are heterostructures of $\mathrm{TiO}_{2}-\mathrm{ZnO}, 50 / 50$ and 10/90 (synthesised by Flame Spray Pyrolysis, FSP), which are expected to be more active than $\mathrm{TiO}_{2}$ under UV and visible radiation as well (literature provides many examples of the effectiveness of heterojunction photocatalysts, synthesized by the combination of two or more oxides (Wang et al. 2014; Liu et al. 2017; Low et al. 2017; Thakur et al. 2018; Lee et al. 2019; Šutka, Järvekülg and Gross 2019; Ungan and Tekin 2019). Besides, different dispersing agents were also used to modify the nature of the coatings in order to avoid the foreseeable agglomeration of the photocatalytic nanoparticles which would have a negative impact on their effectiveness. These dispersions have been applied as coatings onto materials used in the Built Heritage, such as lime mortar, limestone, granite and sandstone.

Waterproofing, self-cleaning and water vapor permeability tests of the treated specimens were performed to evaluate the effectiveness of the coatings. Their photocatalytic activity was also monitored through $\mathrm{NO}_{\mathrm{x}}$ abatement measurements. Durability of the applied coatings after accelerated climatic ageing was also assessed and discussed.

\section{Materials and methods}

\subsection{Materials}


As photocatalysts, nanoparticles of the two heterostructures of $\mathrm{TiO}_{2}-\mathrm{ZnO}$ (weight/weight 50/50 and 10/90) were synthesized by Flame Spray Pyrolysis at Lurederra Technological centre. Organometallic precursors (ethyl hexanoates, acetylacetonates, butoxides and propoxides) were used. The solvents used include isopropylic alcohol, toluene, xylene and acetic acid. The precursor mixture prepared included both the precursor for $\mathrm{Ti}$, and the precursor for $\mathrm{Zn}$ as well as solvents; everything together in one liquid specifically adjusted regarding the composition of the final mixed oxide defined (metal proportions of $\mathrm{Ti}$ and $\mathrm{Zn}$ to result in nano-particles $\mathrm{TiO}_{2}$-ZnO 50/50 and 10/90), the viscosity for suitable atomisation in the flame, and the calorimetric properties to achieve an appropriate combustion and temperature during the process. The equipment used was based on Liquid-Feed Flame Spray Pyrolysis (LFFSP) technology, where a liquid precursor mixture is combined with a dispersing gas to generate droplets in a flame. The nanometric droplets, after solvent evaporation and nucleation, result in solid nanoparticles of the desired composition; and finally, a carrier gas is in charge of the transport and cooling of the generated nanoparticles from pyrolysis area to specific filter bags where the nanopowders are retained. Precursor flows were in the rate $40-80 \mathrm{~mL} / \mathrm{min}$, and dispersion gas between 60 $80 \mathrm{~L} / \mathrm{min}$. The nozzle pressure was typically around 2-4 bar. With the aim of removing any trace of non-desirable adsorbed compounds residual from the synthesis of the active agents, nanoparticles were calcined at $500^{\circ} \mathrm{C}$ prior to their use.

As superhydrophobic medium, a 3D structure was prepared in TECNAN. This 3D formulation is commercialized as Tecnadis Aquashield Forte ${ }^{\circledR}$, and the technical sheet defines as a low viscosity colourless, translucent liquid, which includes ceramic nanooxides (of around $15 \mathrm{~nm}$ of diameter) responsible for the superhydrophobic effect. Besides, the active $\mathrm{TiO}_{2}$ - $\mathrm{ZnO}$ nanoparticles are dispersed in isopropanol, which will first help to penetrate the substrate distributing the active ingredients over the target surface, and then, it will evaporate after the application, yielding a formulation compatible with any porous constructive substrate. Apart from the active $\mathrm{TiO}_{2}-\mathrm{ZnO}$ nanoparticles, the mentioned liquid formulation includes additives for stabilisation (with the main objective of preventing nanoparticles from agglomeration) and for the creation of a light matrix, partially linking the ceramic nano-oxides and resulting in a 3D structure which preserves the natural breathability of the porous substrates. The ceramic nano-oxide particles used present some reactive hydroxyl groups on their surface enabling some partial bonding.

Porous substrates corresponding to building materials were selected: air lime mortars, limestone, sandstone and granite. The stones were supplied by DICONA S.A.. This company was responsible for the quarrying and cutting of the specimens. Due to the processes of cutting, the surface of the specimens was different. Therefore, the only available surface characteristics of the specimens were: very rough surface for sandstone, moderate superficial roughness for limestone, and smooth surface for 
granite (horizontal contours can be seen in Fig. S1, Supplementary material). Air lime mortars were prepared to this aim by using a CL-90 calcitic air lime (Cal Industrial S.A. Calinsa, Navarra). Binder/aggregate and water/binder weight ratios were 1:4.5 and 1.1:1, respectively. A standard siliceous sand (from IETCC) was used as aggregate (particle size $<2 \mathrm{~mm}$ ). The granulometric distribution of this sand has been published elsewhere (Navarro-Blasco et al. 2013) and is also available on the website of the Eduardo Torroja Instituto de Ciencias de la Construcción (https://www.ietcc.csic.es/en/arena-normalizada/). Fresh mortars were moulded into cylindrical containers (diameter $3 \mathrm{~cm}$ ) and, after hardening of 90 days at $20 \circ \mathrm{C}$ and $60 \%$ $\mathrm{RH}$, slices of $1 \mathrm{~cm}$ of thickness were obtained as substrates to apply the coatings. Rectangular-shaped specimens $(5 \times 5 \times 3 \mathrm{~cm})$ of the different lithotypes were supplied by DICONA.

Semiquantitative mineralogical composition of the stony substrates was ascertained by X-ray diffraction. Limestone was Marbella limestone, from Murcia, Spain $\mathbf{9 9 . 5 \%}$ calcite; $0.5 \%$ quartz). The sandstone was extracted from Lleida, Spain (39\% calcite, $41 \%$ dolomite, $20 \%$ quartz). The granite was from Porriño, Spain (28\% quartz, 53\% alkali feldspar (namely $11 \%$ albite, $22 \%$ andesine, $20 \%$ microcline), $6.5 \%$ pyroxene, $0.5 \%$ zirconium oxide, $12 \%$ biotite and muscovite). Density values of the stones were $2.670 \mathrm{~g}$ $\mathrm{cm}^{-3}$ (limestone); $2.302 \mathrm{~g} \mathrm{~cm}^{-3}$ (sandstone) and $2.721 \mathrm{~g} \mathrm{~cm}^{-3}$ (granite), whereas the mortar showed a density of $1.464 \mathrm{~g} \mathrm{~cm}^{-3}$. Open porosity values (water accessible porosity as measured by hydrostatic balance) were $6.62 \%, 15.54 \%$ and $1.24 \%$, respectively, for limestone, sandstone and granite, and $30.63 \%$ for air lime mortar.

Total porosity values were obtained by mercury intrusion porosimetry (see details about the equipment in Navarro-Blasco et al. 2013) and were $8.61 \%$ (limestone), 20.85\% (sandstone), 1.69\% (granite) and $41.54 \%$ (lime mortar).

Different dispersing agents were tested to optimize the stability and efficiency of the dispersions to be applied as coatings. Namely, polynaphtalenesulfonate (PNS), polycarboxylate ether (PCE), melamine sulfonate (MEL) and polyacrylate (PA) were selected. The chemical composition and molecular architecture of these compounds have been reported elsewhere (Duran et al. 2018; Pérez-Nicolás et al. 2018).

\subsection{Methods}

\subsubsection{Characterization of the photocatalytic nanoparticles.}

The powder compounds of the nano-heterostructures $\mathrm{TiO}_{2}-\mathrm{ZnO}(50 / 50$ and $10 / 90)$ were characterized and the average diameter of the particles determined by physisorption of $\mathrm{N}_{2}$ (Micromeritics ASAP 2020, Norcross, GA, USA) according to the BET

algorithm. X-ray diffraction (Bruker D8 Advance, Bremen, Germany) patterns were collected to determine the crystalline phase purity of the nanoparticles. 
The diffuse reflectance (DR) UV-Vis spectra were recorded at a rate of $30 \mathrm{~nm} \mathrm{~min}{ }^{-1}$ with steps of $0.5 \mathrm{~nm}$ using a Varian Cary 1E instrument. Electron paramagnetic resonance (EPR) spectra were recorded in an EMXmicro (Bruker) spectrometer, in order to detect the concentration of $\cdot \mathrm{OH}$ or $\cdot \mathrm{O}_{2}^{-} \cdot 5,5$-dimethyl-1-pyrroline- $\mathrm{N}$-oxide (DMPO) was used as spin-trap agent. The experiments were conducted at room temperature, being the samples dispersed in $45 \mathrm{mM}$ DMPO aqueous (for detecting $\cdot \mathrm{OH}$ ) or methanol (for detecting $\cdot \mathrm{O}_{2}{ }^{-}$) solution and irradiated during $15 \mathrm{~min}$ with a Xe lamp (artificial sunlight). The steady-state photoluminescence (PL) emission spectra were collected on a FLS920 Fluorimeter (Edinburgh Instrument Ltd, Livingston, UK).

Activity of the nanoparticles was assessed by means of the $\mathrm{NO}_{\mathrm{x}}$ abatement, in a laminar-flow reactor (ISO 2016). Different types of illumination were applied: UV-vis and strictly visible (guaranteed by the use of a cut-off filter) radiation. Illumination source was a Osram Ultravitalux $300 \mathrm{~W}$ lamp, according to the specifications of intensities reported elsewhere (Pérez-Nicolás et al. 2017).

The procedure was applied as follows: an initial concentration of $\mathrm{NO}$ of $500 \mathrm{ppbv}$ at a $3.0 \mathrm{~L} \cdot \mathrm{min}^{-1}$ flow was set up and left under dark conditions for 10 minutes, to disregard adsorption processes on the samples. Then, the illumination was switch on and by means of a chemiluminescence detector (Environnement AC32M, Geneva, IL, USA) continuous monitoring of the $\mathrm{NO}$ and $\mathrm{NO}_{2}$ concentrations were recorded. Samples were irradiated for 30 minutes and then illumination source was switch off, registering the recovering of the initial NO values.

In all instances experimental measurements were carried out by triplicate for each one of the nanoparticle compositions. The average values have been reported.

\subsubsection{Obtaining of active multifunctional coatings: assessment of their efficiency}

The efficiency of the photocatalytic nanoparticles and their compatibility with the 3D hydrophobic structure were assessed. Therefore, active dispersions were obtained at the $\mathrm{pH}$ of the either alcoholic $(\mathrm{pH} 4.7)$ or superhydrophobic 3D structure $(\mathrm{pH} \mathrm{5.3),}$ without modifying the values. Three groups of samples were obtained and tested:

i) a control group of the untreated specimens (lime mortar, sandstone, limestone and granite):

ii) a group of coatings were obtained and applied by dispersing solid photocatalytic nanoparticles in alcoholic (isopropanol) solutions $(1 \% \mathrm{w} / \mathrm{v}$ ) with mechanical stirring for 5 minutes, with the aim of assessing the individual effect of each one of the photocatalysts;

iii) Finally, multifunctional coatings were prepared mixing solid photocatalytic nanoparticles in superhydrophobic 3D dispersions $(1 \% \mathrm{w} / \mathrm{v})$ with mechanical stirring for 5 minutes. 
All the coatings were applied by simple deposition of the active dispersion on the substrates in horizontal position. Using a pipette, $1 \mathrm{~mL}$ of the active dispersions was poured in order to cover the exposed upper surface of the specimens. Before testing, substrates were stored for $24 \mathrm{~h}$ under laboratory conditions to allow the drying of the sample. Three similar specimens for each one of the applied coatings were obtained and then tested to guarantee the representativeness of the experimental values.

Water repellency was assessed in these samples by means of the determination of the water contact angle (WCA). To this purpose, an instrument (OCA 15EC Dataphysics, Filderstadt, Germany) was employed. Droplets of $5 \mu \mathrm{L}$ deionized water were poured and monitored during $10 \mathrm{~s}$, in order to achieve reliable data (Fronzi, Assadi and Hanaor 2019). Five different measurements for each one of the surfaces were carried out.

Photocatalytic activity was determined by the monitoring of the $\mathrm{NO}_{\mathrm{x}}$ abatement of the treated specimens, as explained before. Water vapor permeability of the treated specimens was also measured to assess the breathability of the applied coatings. A procedure based on the EN 1015-19 norm (UNE-EN 1999) was followed, using a saturated $\mathrm{KNO}_{3}$ solution to determine the water vapor flux by weighing the samples.

\subsubsection{Incorporation of the superplasticizers (SPS)}

The role of the different dispersing agents was assessed. Dispersing agents were additionally incorporated to enhance the distribution of the photocatalytic nanoparticles in SPHB dispersions with $\mathrm{TiO}_{2}-\mathrm{ZnO}$ nanoparticles - as detailed in 2.2.1 (iii) - . A constant $1 \% \mathrm{w} / \mathrm{w}$ percentage with respect to the weight of photocatalyst of the dispersing agents (polycarboxylate ether (PCE), melamine sulfonate (MEL), polynaphtalenesulfonate (PNS) and polyacrylate (PA)) was added and magnetically stirred (5 minutes) to obtain dispersions that were later applied as active coatings. As explained before, water repellency and photocatalytic activity of the treated specimens were assessed. Average values of the three tested specimens per coating were reported.

\subsubsection{Optimization of the coatings.}

In order to optimize the coatings, several parameters were modified in the dispersions, namely the $\mathrm{pH}$, the percentage of the photocatalyst and the percentage of the superplasticizer. Changes in the $\mathrm{pH}$ (towards alkaline media) would involve a more stable colloidal dispersion of the nanoparticles, given that dispersing agents have ionizable groups under that $\mathrm{pH}$ (carboxylate, sulfonate ...), contributing by electrostatic repulsions to minimize the nanoparticles agglomeration. The rationale behind these modifications was to achieve dispersions with: i) $\mathrm{pH}$ value as close as possible to neutral $\mathrm{pH}$ to allow the coating application in the wider range of substrates as possible; ii) an acceptable load of photocatalyst, under condition of no changes in gloss or color after the application and good cost/efficiency ratio; iii) as low a percentage of 
dispersing agent as possible, to reduce the final price of the coating; iv) the long-term stability of the dispersions, meaning either no sedimentation or easiness of redispersion.

Different trials were made after varying: a) $\mathrm{pH}$, by small changes after increasing additions of $20 \% \mathrm{w} / \mathrm{w}$ solution of $\mathrm{NaOH}$; b) percentage of photocatalyst, ranging between 1 and $5 \%$ and later application on some substrates to observe individual changes in gloss or color; and c) percentage of dispersing agent, from 1 up to 6\%. For these trials, time for sedimentation (over 72 hours), phase segregation (after ultrasonication for $15 \mathrm{~min}$ of the dispersion) and redispersibility were evaluated. The two best coatings according to the aforementioned criteria were selected and applied onto the different stony substrates (by triplicate).

Particle size distribution (with a Malvern Mastersizer laser diffractometer, Malvern, UK) and zeta potential (ZetaProbe Analyzer Colloidal Dynamics, Ponte Vedra Beach, FL, USA) of the active dispersions were measured. Hydrophobicity of the treated surfaces was assessed by the WCA and photocatalytic activity by the $\mathrm{NO}_{\mathrm{x}}$ abatement, as reported in the previous section.

Self-cleaning tests were also performed. Degradation of Rhodamine B was studied. With a micropipette $0.2 \mathrm{~mL}$ of Rhodamine $B$ solution $\left(10^{-3} \mathrm{M}\right)$ was poured on the surface of the specimens. Samples were then irradiated (UV-vis illumination with Osram Ultravitalux $300 \mathrm{~W}$ lamp) and the loss of color was observed at different times over 48 h. CIELAB spectrophotometer (Konica Minolta, Williams Drive Ramsey, NJ, USA) was used to quantify the color and lightness changes at 0, 24 and $48 \mathrm{~h}$.

Durability of the applied coatings was assessed after exposure to accelerated climatic ageing. A Xenolab $\mathrm{CCl}(\mathrm{CCl}$, Barcelona, Spain) climatic chamber was used. Cycles included changes in the temperature, relative humidity, UV-vis irradiation and rain periods. Steps of 25 minutes were set up with the following conditions: 1) $35^{\circ} \mathrm{C}$, UV-vis radiation, $40 \% \mathrm{RH}$; 2) $20^{\circ} \mathrm{C}, 90 \% \mathrm{RH}$, rain water; 3) $0^{\circ} \mathrm{C}, 60 \% \mathrm{RH}$; 4) $-5^{\circ} \mathrm{C}, 50 \% \mathrm{RH}$. These steps were continuously repeated, keeping samples subjected to accelerated ageing for 3 days. After the ageing, the photocatalytic activity (NOx abatement) and the water repellency assessment (WCA) of the weathered samples was carried out. Fig. 1 includes a scheme of the study. 


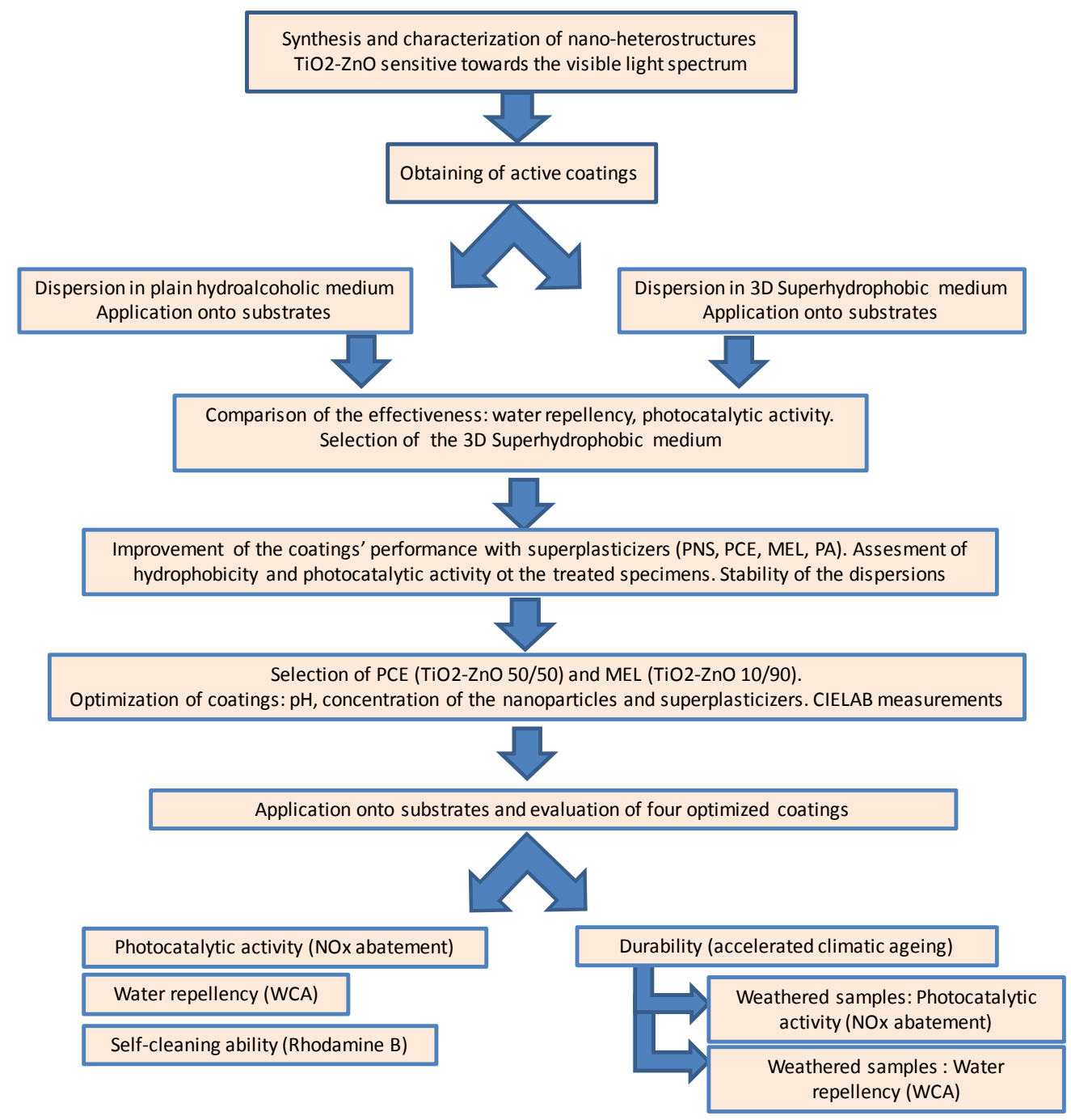

Figure 1. Scheme of the experimental work steps.

\section{Results and discussion}

\subsection{Powdered nano-heterostructures $\mathrm{TiO}_{2}-\mathrm{ZnO} 50 / 50$ and $10 / 90$}

Specific surface areas of the nano-heterostructures $\mathrm{TiO}_{2}-\mathrm{ZnO} 50 / 50$ and $10 / 90$ were 84.8 and $79.7 \mathrm{~m}^{2} / \mathrm{g}$, and the average size was calculated to be 15 and $19 \mathrm{~nm}$, respectively. These data, together with the crystalline phase analysis, have been reported in a previou work (Speziale et al. 2019). The light absorption properties of the heterostructures as well as of the raw materials $\left(\mathrm{TiO}_{2}\right.$ and $\mathrm{ZnO}$ ) were studied by DR UVVis spectroscopy (Fig. 2). As expected, all samples exhibit a strong absorption in the UV region in the 285 - $350 \mathrm{~nm}$ range (Marci et al. 2001; Henderson 2011). A red shift in the onset of the absorption is observed from $\mathrm{TiO}_{2}$ to $\mathrm{ZnO}$. In the case of the heterostructures, this shift is more obvious for the $\mathrm{TiO}_{2}-\mathrm{ZnO} 50 / 50$ sample and this finding can be related to the higher number of heterojunctions formed in these nanoparticles as a consequence of the stoichiometry of the raw materials. 


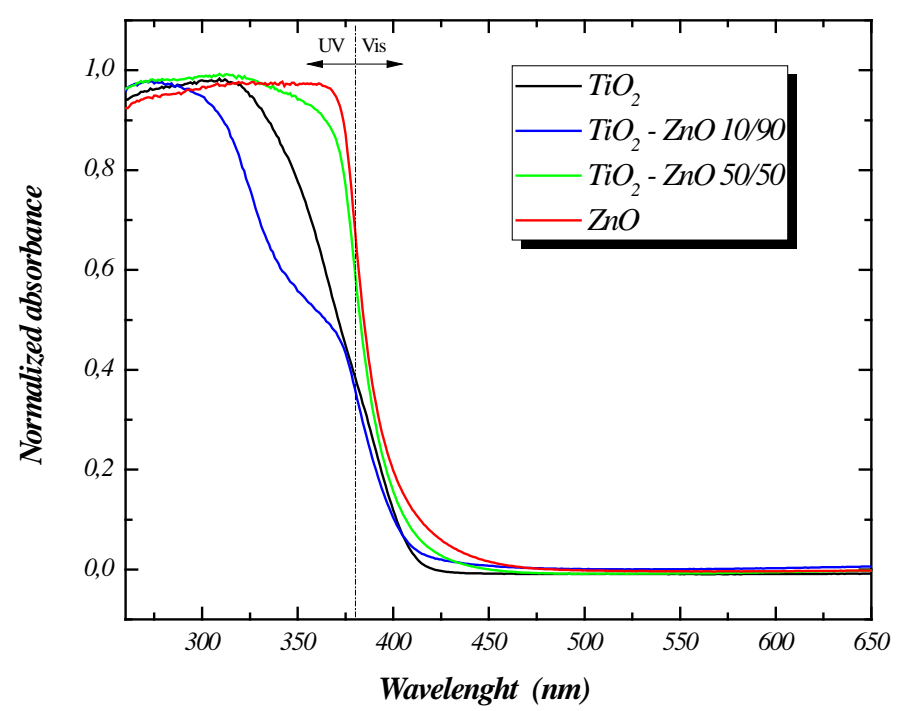

Figure 2. The UV-Vis absorption spectra for the $\mathrm{TiO}_{2}, \mathrm{ZnO}$ and $\mathrm{TiO}_{2} / \mathrm{ZnO}$ samples.

The key of photocatalysis is the participation of reactive oxygen species (ROS) in the chemical oxidative processes (Balbuena, Cruz-Yusta and Sánchez 2015). Thus, it results of interest to know the ability of the samples here studied to produce ROS species. The generation of $\cdot \mathrm{OH}$ and $\cdot \mathrm{O}_{2}^{-}$radicals, under UV-Vis light, was studied by EPR measurements using DMPO as the spin-trapping agent. In Fig. 3a, a quartet of peaks with a 1:2:2:1 intensity ratio was observed. This signal is characteristic of DMPO-.OH adduct (Lipovsky et al. 2012), being the intensity slightly higher for $\mathrm{TiO}_{2}$ and $\mathrm{TiO}_{2}-\mathrm{ZnO}$ $50 / 50$ samples compared to that of $\mathrm{ZnO}$. However, the signal is scarcely appreciated for the $\mathrm{TiO}_{2}-\mathrm{ZnO} 10 / 90$ sample. When the samples are irradiated in the methanol solution, the generation of the DMPO- $\mathrm{O}_{2}{ }^{-}$adduct is corroborated by the existence of four peaks (Fig. 3b) (Lipovsky et al. 2012). The $\mathrm{TiO}_{2}$-based samples exhibit a better ability to generate peroxide radicals, which is in line with the fact that $\mathrm{CB}$ in $\mathrm{TiO}_{2}$ is located around $0.32 \mathrm{eV}$ upper to that of $\mathrm{ZnO}$ (Conesa 2012; Hernández et al. 2014), facilitating the $\mathrm{O}_{2}+\mathrm{e} \rightarrow \mathrm{O}_{2}^{-}$reaction (Harbour, Tromp and Hair 1985). Interestingly, the intensity of the DMPO-. $\mathrm{O}_{2}{ }^{-}$increases for the $\mathrm{TiO}_{2}-\mathrm{ZnO}$ heterostructures. 

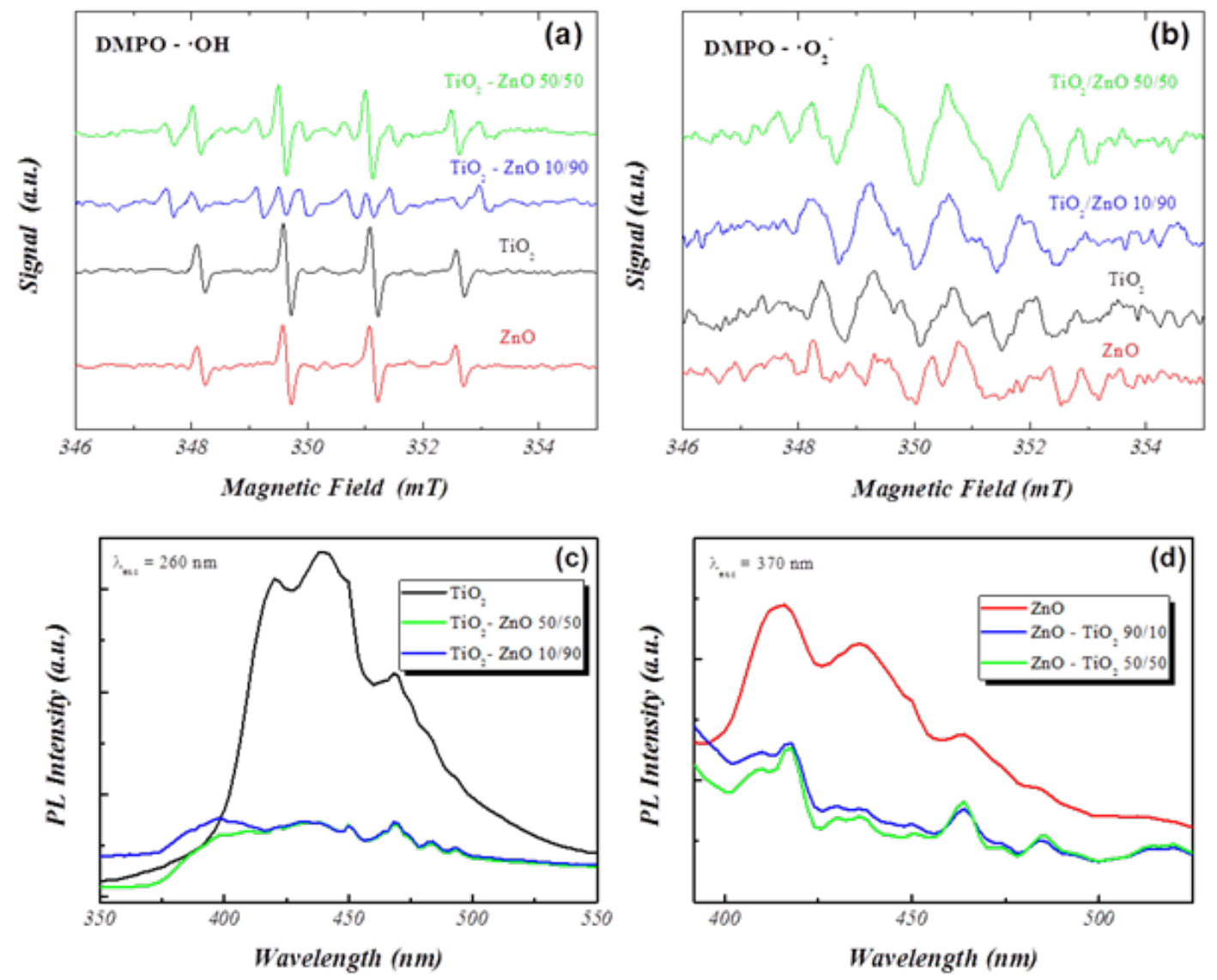

Figure 3. DMPO spin-trapping EPR spectra of the $\mathrm{TiO}_{2}, \mathrm{ZnO}$ and $\mathrm{TiO}_{2}-\mathrm{ZnO}$ samples under UV-Vis light irradiation in (a) aqueous solution for $\bullet \mathrm{OH}$ and (b) methanol solution for $\bullet \mathrm{O}_{2}^{-}$. Photoluminescence (PL) spectra of the $\mathrm{TiO}_{2}, \mathrm{ZnO}$ and $\mathrm{TiO}_{2}-\mathrm{ZnO}$ samples. Excitation wavelength: (c) 260 and (d) $370 \mathrm{~nm}$.

Photoluminescence spectroscopy (PL) studies were carried out in order to go in depth about the electronic properties of the samples. The PL technique is useful to get insight of the photocharge generation, transfer and separation efficiency of $\mathrm{TiO}_{2}$ and $\mathrm{ZnO}$ photocatalysts (Zhang et al. 2000). Fig. $3 \mathrm{c}$ and $3 \mathrm{~d}$ shows the corresponding spectra obtained for the photocatalysts, exhibiting a broad multicomponent PL peak in the 400-480 $\mathrm{nm}$ region. Of importance, the intensity of the signal clearly decreases for $\mathrm{TiO}_{2}-\mathrm{ZnO}$ nanoparticles compared with $\mathrm{TiO}_{2}$ or $\mathrm{ZnO}$. The measure of a high intensity signal is typical for large radiative recombination rate of the electrons and holes in the semiconductor. Therefore, in the case of the $\mathrm{TiO}_{2}-\mathrm{ZnO}$ samples, the decrease in the $\mathrm{PL}$ signal should be associated to a new deactivation pathway of the photocharges lessening the recombination of charge carriers, thanks to the heterojunction formed between the $\mathrm{CB}$ and $\mathrm{CV}$ bands of $\mathrm{TiO}_{2}$ and $\mathrm{ZnO}$ when both compounds are mixed. Thus, when photocatalyst is light irradiated, an $\mathrm{e}^{-} / \mathrm{h}^{+}$pair is formed by photon absorption and the interface facilitates the charge separation. In the case of $\mathrm{TiO}_{2}-\mathrm{ZnO}$ systems, the electron moves to the $\mathrm{ZnO}$ side while the hole will be located at the $\mathrm{TiO}_{2}$ side (Conesa 2012). The fact that the electron-hole pair recombination is lessened in $\mathrm{TiO}_{2}-\mathrm{ZnO}$ 
samples explains its higher ability observed in the generation of active radicals, mainly peroxide radicals (Fig. 3b). Therefore, a higher potential photocatalytic activity should be expected for these mixtures.

This was confirmed by assessing the photocatalytic activity of the obtained nanoheterostructures. It was determined by monitoring the nitrogen oxides degradation (Fig. 4). The results confirmed the activity of the synthesized heterostructures, which were seen to be more active than the pure $\mathrm{TiO}_{2}$ and $\mathrm{ZnO}$ nanoparticles under UV-vis and strictly visible light as well.

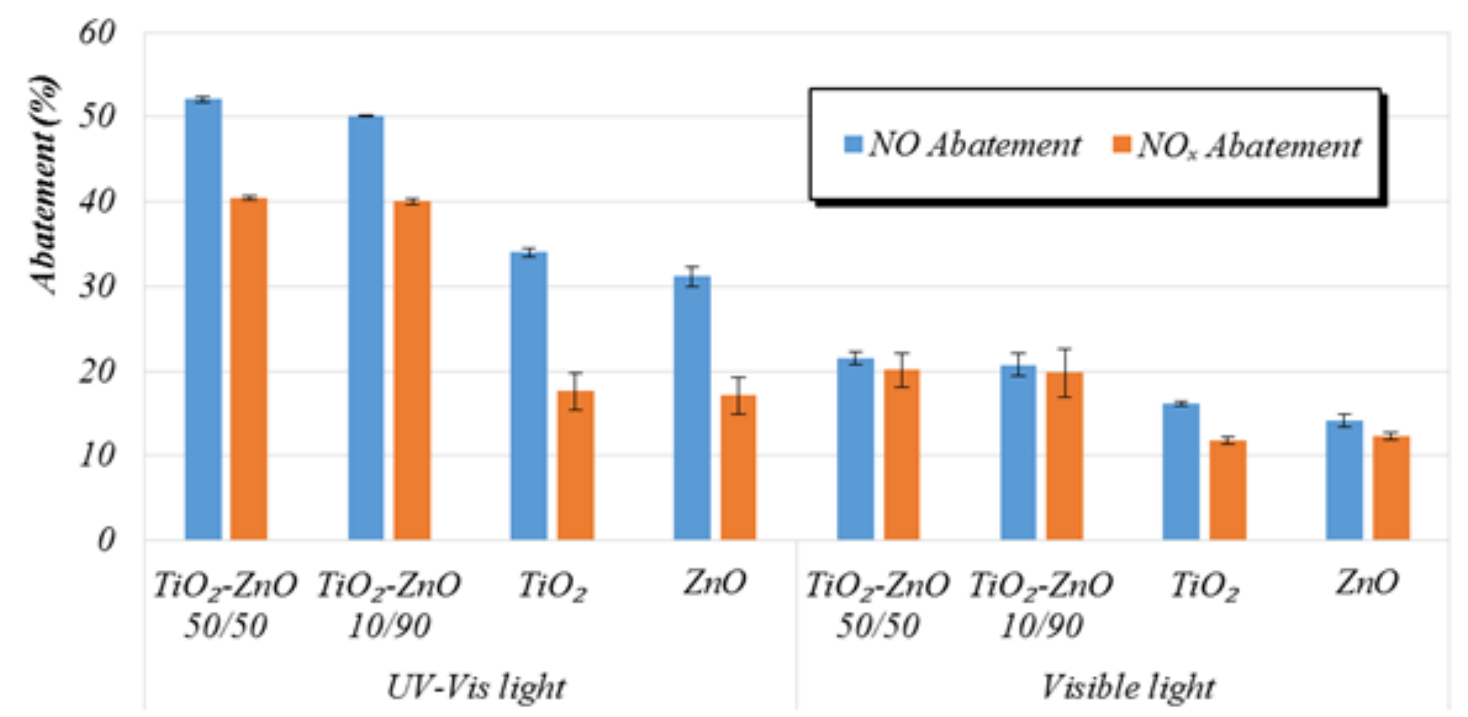

Figure 4. $\mathrm{NO}$ and $\mathrm{NO}_{\mathrm{x}}$ abatement of the powdered nano-heterostructures and raw materials under UV-vis and strictly visible radiation.

\subsection{Hydroalcoholic and superhydrophobic dispersions}

According to the procedure described in the Materials and methods section, the nanoparticles were vehiculized in two different dispersions, in a simple alcoholic solvent and in a dispersion including the superhydrophobic 3D agent. The dispersions were applied as coatings onto the target building materials of the Cultural Heritage.

Hydrophobicity of the samples was tested by means of the determination of the static water contact angle. Five measurements per specimen were carried out on the control and treated specimens as well. Results are collected in Table 1. Untreated samples of very porous substrates, as sandstone, lime mortar and limestone, either did not allow the measurement of the contact angle, since the drop of water was immediately absorbed by the substrate, or the measured WCA was extremely low. On the contrary, for untreated granite, which is the substrate with the lowest porosity, WCA was $88.3^{\circ}$. In the case of hydroalcoholic coatings (denoted as H samples), WCA could not be measured in most of samples, irrespective of the type of nanoparticles. In the case of 
treated granite, the hydrophilicity of the nanoparticles resulted in a WCA reduction, sharper for $\mathrm{TiO}_{2}-\mathrm{ZnO}$ 10/90 nanoparticles.

A clear improvement of the hydrophobicity of the surfaces was observed after the treatment with superhydrophobic coatings (SPHB samples). WCA were higher than $90^{\circ} \mathrm{C}$ in all cases, evidencing the ability of the coatings to prevent the wettability of the surfaces. No significant differences were observed between the two types of nanoparticles.

Table 1. Static water contact angle of the treated specimens.

\begin{tabular}{|c|c|}
\hline Specimen & Contact angle $\left({ }^{\circ}\right)$ \\
\hline Sandstone-Control & $11.5 \pm 0.3$ \\
\hline Sandstone-H 50/50 & $11.0 \pm 0.4$ \\
\hline Sandstone-H 10/90 & - \\
\hline Sandstone-SPHB 50/50 & $130.0 \pm 2.2$ \\
\hline Sandstone-SPHB 10/90 & $103.0 \pm 1.0$ \\
\hline Lime mortar-Control & - \\
\hline Lime mortar-H 50/50 & - \\
\hline Lime mortar-H 10/90 & - \\
\hline Lime mortar-SPHB 50/50 & $121.0 \pm 2.8$ \\
\hline Lime mortar-SPHB 10/90 & $93.0 \pm 2.3$ \\
\hline Granite-Control & $88.3 \pm 2.9$ \\
\hline Granite-H 50/50 & $65.5 \pm 3.5$ \\
\hline Granite-H 10/90 & $36.2 \pm 0.4$ \\
\hline Granite-SPHB 50/50 & $128.0 \pm 2.1$ \\
\hline Granite-SPHB 10/90 & $131.0 \pm 1.0$ \\
\hline Limestone-Control & - \\
\hline Limestone-H 50/50 & - \\
\hline Limestone-H 10/90 & - \\
\hline Limestone-SPHB 50/50 & $104.0 \pm 2.9$ \\
\hline Limestone-SPHB 10/90 & $109.0 \pm 3.4$ \\
\hline
\end{tabular}

Water vapor permeability was also monitored along 7 days. Results showed that the SPHB coatings allowed the breathability of the specimens after application. Comparative values showed hardly differences between the uncoated and coated specimens (for example, uncoated lime mortar showed a permeability of $2.99 \times 10^{-11} \mathrm{Kg}$ $\mathrm{m}^{-1} \mathrm{~s}^{-1} \mathrm{~Pa}^{-1}$ and Lime mortar-SPHB $50 / 50$ of $3.02 \times 10^{-11} \mathrm{Kg} \mathrm{m}^{-1} \mathrm{~s}^{-1} \mathrm{~Pa}^{-1}$; almost identical values of permeability were determined for uncoated limestone, $2.58 \times 10^{-11} \mathrm{Kg} \mathrm{m}^{-1} \mathrm{~s}^{-1}$

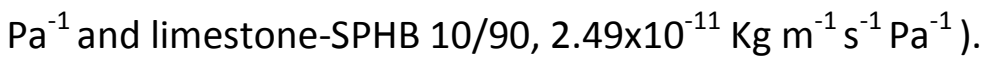

$\mathrm{NO}_{\mathrm{x}}$ abatement was monitored as a way of assessing the photocatalytic activity of the coatings. The $\mathrm{NO}_{x}$ degradation caused by untreated specimens of the sandstone, lime mortar, granite and limestone was also studied as control samples. However, none of the specimens gave rise to a significant $\mathrm{NO}_{x}$ decrease. 


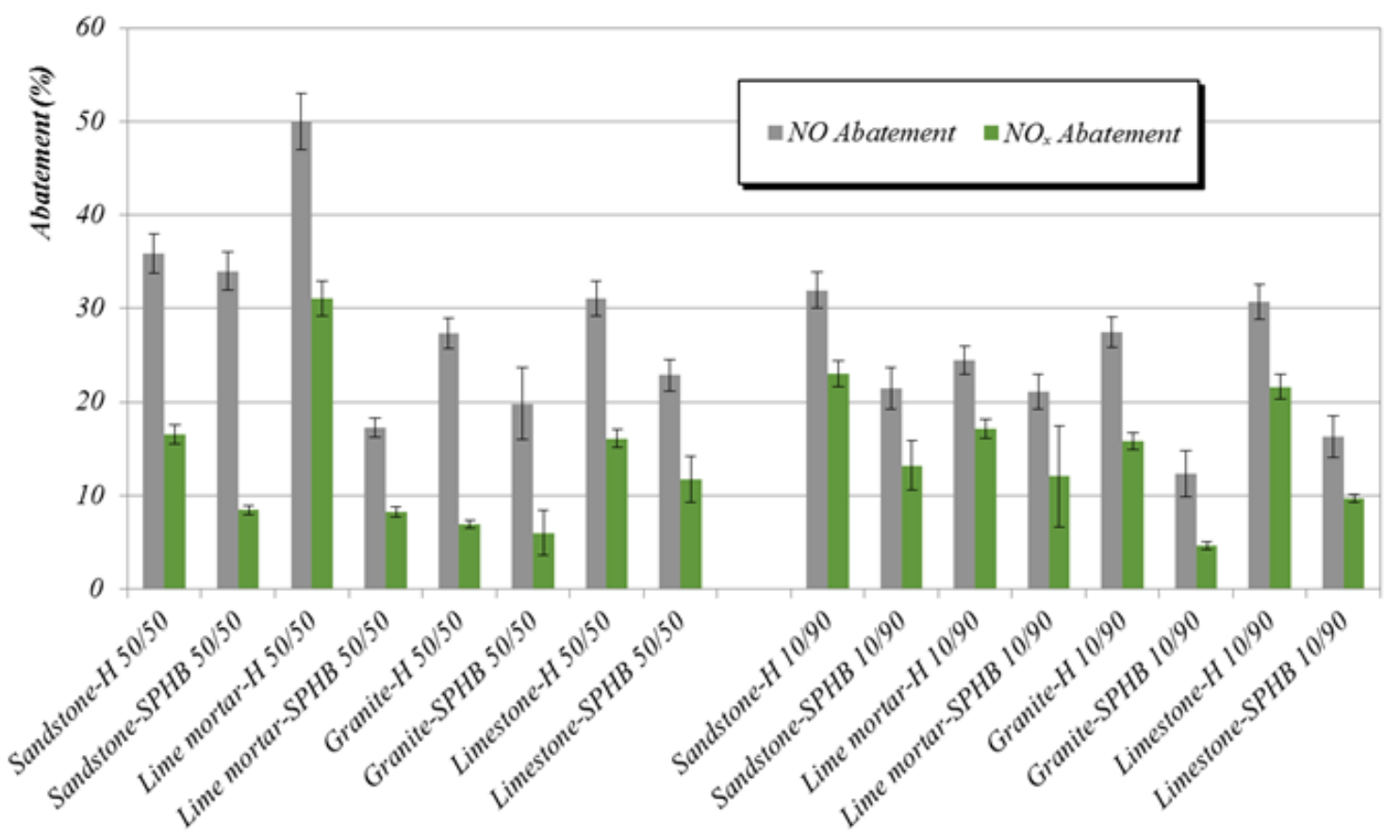

Figure 5. $\mathrm{NO}_{\mathrm{x}}$ degradation (under UV-vis illumination) of the substrates treated with hydroalcoholic $(\mathrm{H})$ or superhydrophobic (SPHB) dispersions of the two tested nanoheterostructures (50/50 and 10/90).

Once the active coatings had been applied, the photocatalytic activity under UV-vis radiation of the specimens was in all instances measurable (Fig. 5). Some of the samples ( 6 over 16 tested specimens) yielded nitric oxide abatement percentages higher than $30 \%$.

For SPHB coatings, rough substrates (sandstone and limestone) removed the highest NOx percentages. The higher roughness would contribute to a better distribution of the photocatalyst, avoiding the electron-hole recombination due to the proximity of the active particles. Results showed that smooth surfaces like granite, coated with SPHB coatings, yielded the lowest photocatalytic activity. For lime mortar, the roughness should increase the activity, but the high porosity might result in absorption of the active particles, thus reducing the exposure of the active photocatalyst to the NO molecules and to the light photons.

Nanoparticles $\mathrm{TiO}_{2}-\mathrm{ZnO}$ 50/50 were able to degrade, on average, more $\mathrm{NO}$ than $\mathrm{TiO}_{2}$ $\mathrm{ZnO}$ 10/90 heterostructures. However, the selectivity was better for $\mathrm{TiO}_{2}-\mathrm{ZnO} 10 / 90$, as depicted in Fig. S2 (Supplementary material). Selectivity was the ratio (expressed as percentage) of $\mathrm{NO}_{\mathrm{x}} / \mathrm{NO}$ and is of importance to assess the full efficiency as photocatalyst of the active compounds (Bloh, Folli and Macphee 2014). When monitoring NO degradation, there are many different pathways leading to the photocatalytic oxidation of the compounds. $\mathrm{NO}_{2}$ release (as intermediate product) appears as one of the main drawbacks of some photocatalytic agents, particularly 
when used as depolluting compounds. If compounds are active enough, then the oxidation will end up forming the non-toxic nitrate. Although in the current work the environmental implications are not the main objective, the higher selectivity values of the 10/90 nanoparticles indicate the best photocatalytic performance of these heterostructures. The presence of $\mathrm{ZnO}$ clearly improves the selectivity of the active photocatalysts.

In all cases, the dispersion of the nanoparticles in the SPHB medium resulted in a photocatalytic effect reduction. To better understand this drop, these dispersions were characterized according to their particle size distribution (PSD) and to their zeta potential.

The PSD of dispersions with nano-heterostructures $\mathrm{TiO}_{2}-\mathrm{ZnO} 50 / 50$ is depicted in Figure 6a. The pattern of the hydroalcoholic dispersion $(\mathrm{H})$ matches a unimodal PSD, with a maximum at $18 \mu \mathrm{m}$. Nevertheless, the dispersion of the photocatalyst in a medium with the SPHB agent resulted in the agglomeration of the nanoparticles, as shown in the curve, in which a maximum at ca. $60 \mu \mathrm{m}$ was observed.

A similar trend towards the agglomeration of the nanoparticles in the SPHB medium was also observed for nano-heterostructures $\mathrm{TiO}_{2}$ - $\mathrm{ZnO}$ 10/90 (Fig. 6b). In the hydroalcoholic medium, $\mathrm{TiO}_{2}-\mathrm{ZnO} 10 / 90$ nanoparticles showed a bimodal distribution with two maximums at 0.3 and $4 \mu \mathrm{m}$ (in any case, lower size of agglomerates than that of the $\mathrm{TiO}_{2}-\mathrm{ZnO} 50 / 50$ ). When dispersed in the SPHB 3D medium, the agglomeration of the nanoparticles was observed, with particle diameter of $30 \mu \mathrm{m}$.

Therefore, the agglomeration of the nanoparticles can be argued to explain the decrease in the photocatalytic activity, since it causes a reduction in the number of active sites of the compounds. Furthermore, the hydrophobic environment is hostile for the largely hydrophilic nanoparticles and can hinder the necessary water access to the photocatalyst, which is essential for the formation of the active oxidizing radicals and therefore for the photocatalytic activity.

Besides, the stability of the SPHB dispersions was not very good. Segregation of the phases and sedimentation of the nanoparticles were observed. Measurements of the zeta potential of the nanoparticles accounted for these findings. In a summarized way, according to the electric double layer model, the external surface around colloidal nanoparticles is constituted by two layers of ions and its charge can be measured as the zeta potential at the shear plane (Plank et al. 2005). Highly positive or negative values of the zeta potential lead to electrostatic repulsions that avoid agglomeration and allow the nanoparticles to be well dispersed (Liu, Chen and Su 2011). Density of the nanoparticles is also critical to establish the minimum potential value to impart stability. 

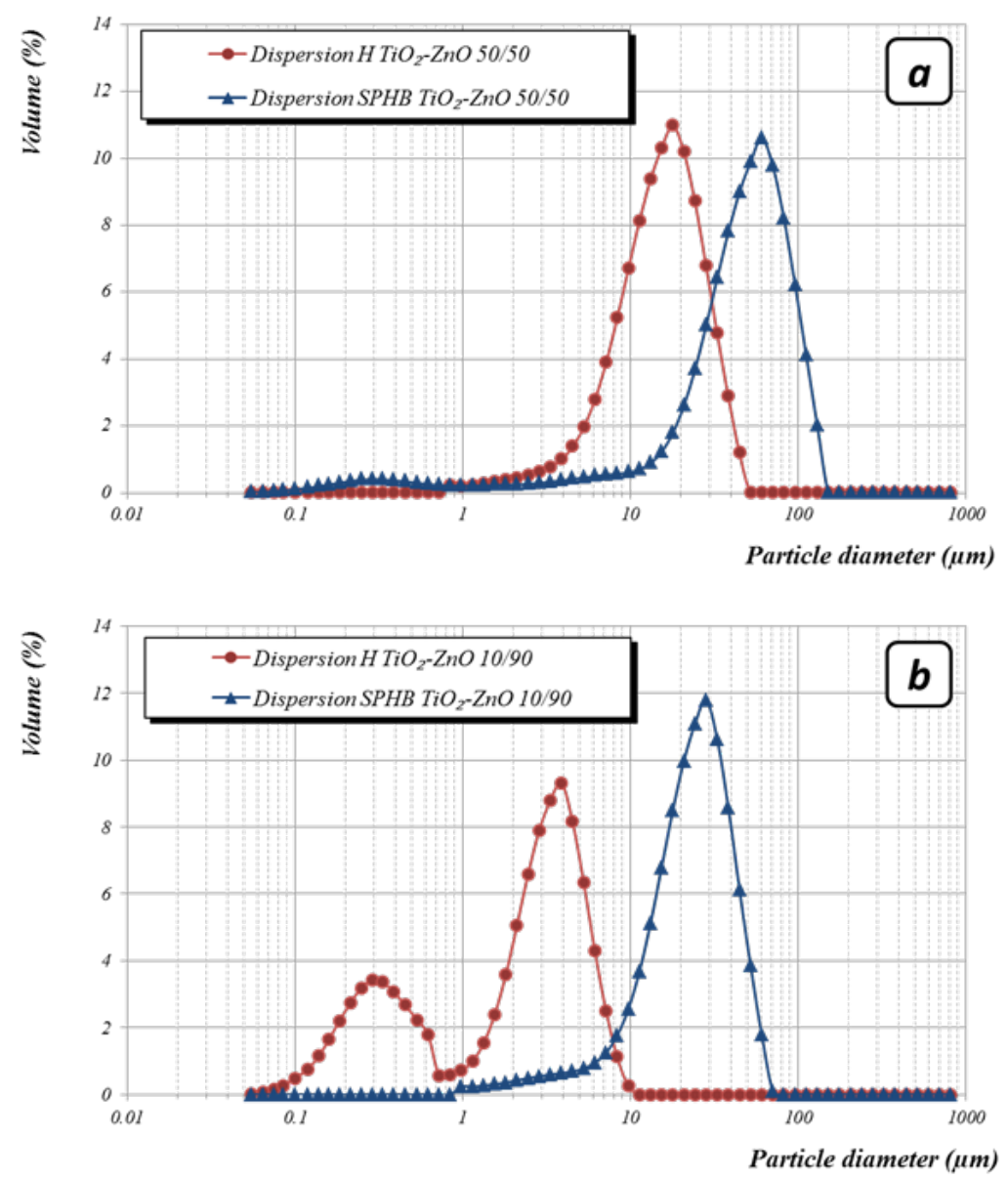

Figure 6. Particle size distribution of the nanoparticles $(1 \% \mathrm{w} / \mathrm{w})$ in $\mathrm{H}$ dispersion or in SPHB dispersion: a) $\mathrm{TiO}_{2}-\mathrm{ZnO} 50 / 50$; b) $\mathrm{TiO}_{2}-\mathrm{ZnO}$ 10/90.

Zeta potential values showed that the SPHB medium decreased the surface charge of the nanoparticles explaining the observed agglomeration and sedimentation (Table 2). The larger particle size of the $\mathrm{TiO}_{2}-\mathrm{ZnO} 10 / 90$ could be the reason why the reduction in zeta potential values was toned down, although further studies would be necessary to clarify this point.

Table 2. Zeta potential values (mean \pm standard deviation, $\mathrm{mV}$ ) of the tested nanoparticles in the different dispersions.

\begin{tabular}{ccc}
\hline Nano-heterostructures & $\begin{array}{c}\text { Hydroalcoholic }(\boldsymbol{H}) \\
\text { suspension }\end{array}$ & $\begin{array}{c}\text { Superhydrophobic } \\
\text { (SPHB) suspension }\end{array}$ \\
\hline $\mathrm{TiO}_{2}-\mathrm{ZnO} \mathrm{50/50}$ & $52.2 \pm 1.2$ & $16.5 \pm 0.8$ \\
$\mathrm{TiO}_{2}-\mathrm{ZnO} \mathrm{10/90}$ & $41.8 \pm 1.0$ & $38.2 \pm 1.6$ \\
\hline
\end{tabular}

\subsection{Improvement of dispersions with superplasticizers}

The previous findings point to the need for the optimization of the dispersions. In a first attempt, the use of dispersing agents (superplasticizers, SPs) may be useful to reduce the nanoparticles agglomeration and thus to increase the activity. Four 
different superplasticizers - polynaphtalenesulfonate (PNS), polycarboxylate ether $(P C E)$, melamine sulfonate (MEL) and polyacrylate (PA) - were thus added in $1 \% \mathrm{w} / \mathrm{w}$ with respect to the nanoparticules, with the aim of preventing nanoparticles from agglomeration. Depending on the molecular architecture and on the chemical composition (especially the presence of ionizable groups), different action mechanisms explaining the activity of the SPs can be invoked (Plank, Sachsenhauser and de Reese 2010). Depending on the $\mathrm{pH}$ value of the colloidal medium, charged functional groups of the SPs can be attached to the surface of the nanoparticles replacing some of the ions of the double layer, giving rise to electrosteric repulsions between the particles, thus avoiding their agglomeration (Plank et al. 2005 ).

Particle size distribution of the SPHB dispersions showed that the addition of the PNS, PCE and MEL reduced the main average particle size diameter of the nanoparticles and the population of agglomerates with diameter larger than 40 microns (Fig. 7). This finding was consistent for the two tested types of nanoparticles, $\mathrm{TiO}_{2}-\mathrm{ZnO} 50 / 50$ (Fig. 7a) and $\mathrm{TiO}_{2}-\mathrm{ZnO}$ 10/90 (Fig. 7b). The other noticeable result was the detrimental incorporation of the polyacrylic acid as superplasticizer: far from improving the PSD, the presence of PA yielded formation of larger agglomerates of nanoparticles.

Photocatalytic activity of the building materials treated with these coatings was assessed. For sandstone (Fig. 8a), the use of superplasticizers showed improvements in the $\mathrm{NO}_{\mathrm{x}}$ degradation for all the superplasticizers except for $\mathrm{PA}$, in good agreement with the observed agglomeration of the particles reported in PSD curves. In the case of $\mathrm{TiO}_{2}-\mathrm{ZnO} 50 / 50$ and for PNS, PCE and MEL-bearing coatings, $\mathrm{NO}_{\mathrm{x}}$ abatement was more than twice the abatement of the coating without dispersing agents. For $\mathrm{TiO}_{2}-\mathrm{ZnO}$ $10 / 90$ coatings with these three superplasticizers, the $\mathrm{NO}_{\mathrm{x}}$ degradation was increased by ca. $50 \%$.

With respect to treated lime mortars, a similar trend was observed (Fig. 8b). Generally speaking, the addition of superplasticizers favored the photocatalytic activity as denoted by the $\mathrm{NO}_{x}$ removal results. The exceptions were again samples with PA, whose poor performance can be explained as a consequence of the promoted agglomeration. For this substrate, coatings with $\mathrm{TiO}_{2}-\mathrm{ZnO} 10 / 90$ and superplasticizers were identified on average as the most active materials. 

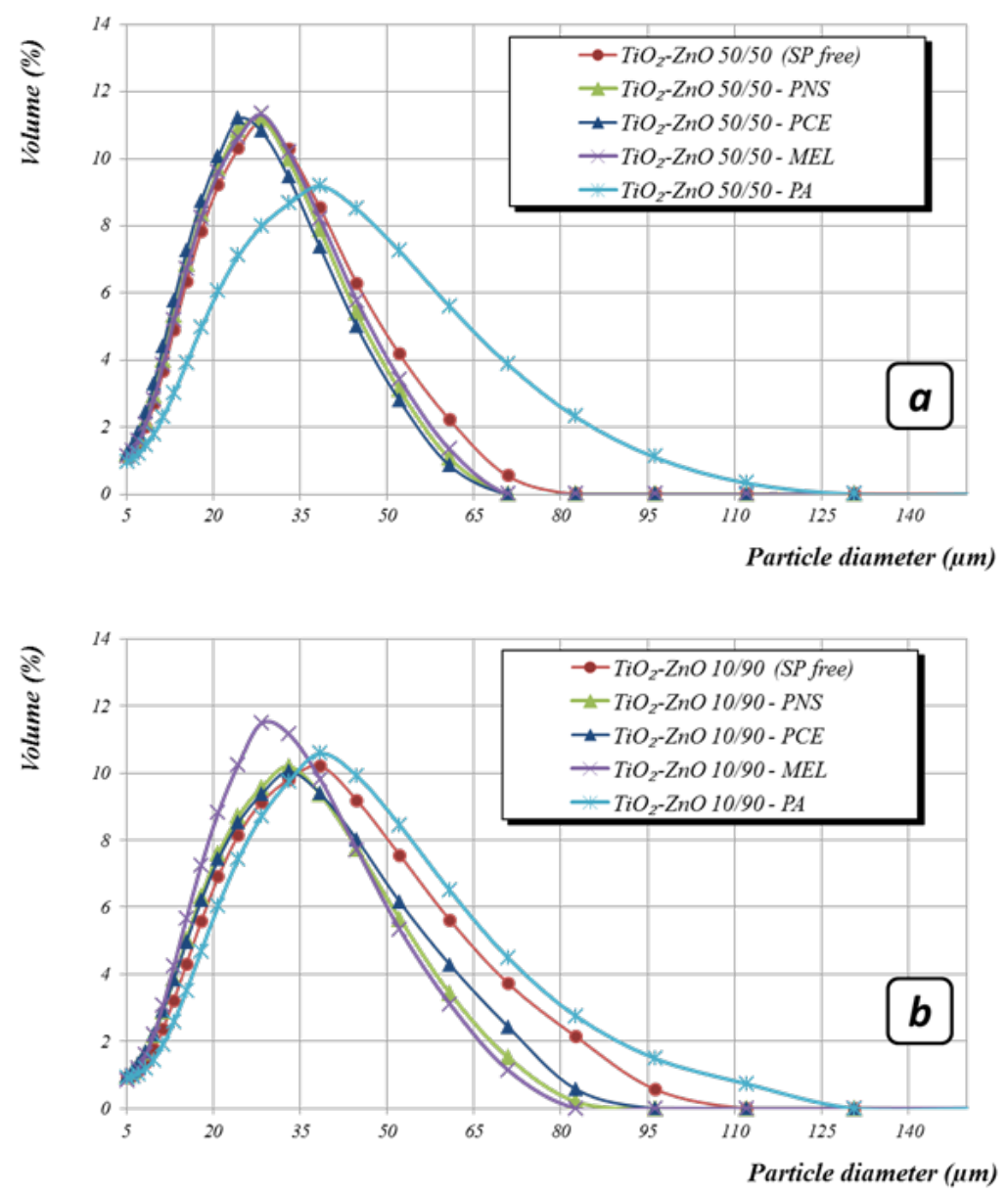

Figure 7. Particle size distribution of the nanoparticles ( $1 \% \mathrm{w} / \mathrm{w})$ in SPHB dispersion with superplasticizers. Control group, superplasticizer-free is also shown: a) $\mathrm{TiO}_{2}-\mathrm{ZnO}$ 50/50; b) $\mathrm{TiO}_{2}-\mathrm{ZnO}$ 10/90.

When coatings with superplasticizers were applied onto granite (Fig. 8c) and limestone (Fig. 8d), improvements in $\mathrm{NO}_{\mathrm{x}}$ degradation were also observed in most of samples. For these two substrates, and in agreement with the previous results, specimens treated with PA-bearing coatings yielded poor NO abatement results.

The addition of the superplasticizers to the coating did not jeopardize the hydrophobicity imparted by the coating to the sandstone. On the contrary, WCA measurements yielded values corresponding to largely hydrophobic surfaces in all cases.

Table 3 shows, as an example, the values of the treated sandstone surfaces for $\mathrm{TiO}_{2}$ ZnO 10/90 coatings, evidencing how the presence of superplasticizers increased the water contact angle. The absence of hydrophilic agglomerates of nanoparticles might be a reason explaining this finding. 

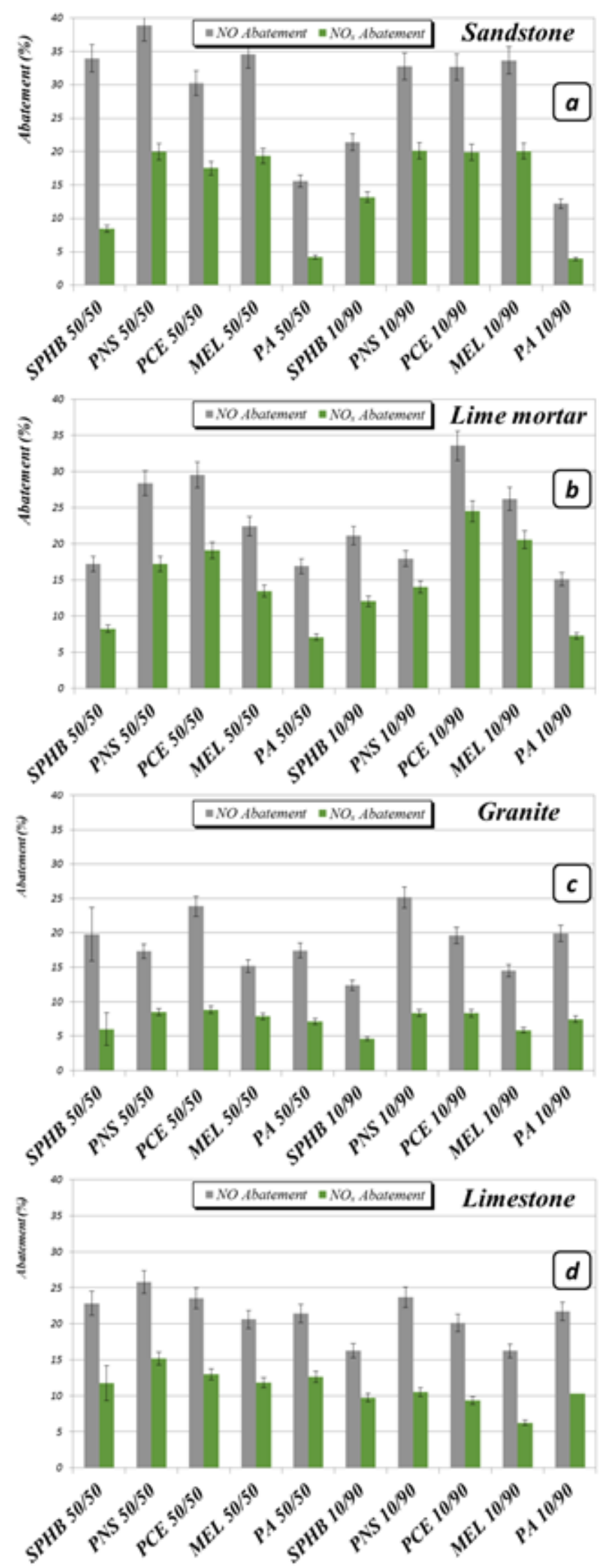

Figure 8. Effect of the different coatings on the nitrogen oxides degradation under UVvis radiation for a) sandstone, b) lime mortar, c) granite and d) limestone as substrate. 
For air lime mortars, in spite of their well-known high porosity, hydrophobicity was guaranteed for all these coatings, with, for example, a water contact angle of $132^{\circ}$ for PCE 10/90 sample.

Adequate hydrophobicity was kept in all these treated surfaces (see, for example, in Table 3 water contact angles measurements for granite samples with the different coatings, in which values higher than $115^{\circ}$ were always determined).

Table 3. Static water contact angle of the sandstone and granite specimens treated with the different coatings.

\begin{tabular}{cc}
\hline Specimen & Contact angle $\left({ }^{\circ}\right)$ \\
\hline Sandstone-SPHB 10/90 & $103.0 \pm 1.0$ \\
Sandstone-PNS 10/90 & $131.7 \pm 1.8$ \\
Sandstone-PCE 10/90 & $132.0 \pm 2.4$ \\
Sandstone-MEL 10/90 & $142.6 \pm 2.3$ \\
Sandstone-PA 10/90 & $119.5 \pm 1.7$ \\
\hline Granite-SPHB 50/50 & $128.0 \pm 2.1$ \\
Granite-PNS 50/50 & $128.1 \pm 1.3$ \\
Granite-PCE 50/50 & $122.8 \pm 2.3$ \\
Granite-MEL 50/50 & $132.8 \pm 2.0$ \\
Granite-PA 50/50 & $120.4 \pm 5.2$ \\
\hline Granite-SPHB 10/90 & $131.0 \pm 1.0$ \\
Granite-PNS 10/90 & $119.9 \pm 2.3$ \\
Granite-PCE 10/90 & $115.6 \pm 1.6$ \\
Granite-MEL 10/90 & $118.7 \pm 3.2$ \\
Granite-PA 10/90 & $124.4 \pm 3.4$ \\
\hline
\end{tabular}

Overall, the results concerning the photocatalytic activity of the coatings with superplasticizers showed that the approaching was appropriate and successful, since for the majority of the treated substrates the activity -in terms of $\mathrm{NO}_{\mathrm{x}}$ removal- was increased while the hydrophobicity of the samples was preserved with high water contact angles.

\subsection{Optimization of the active coatings}

\subsubsection{Stability and redispersibility of the coatings}

The final objective of this section was to obtain dispersions to be applied as coatings which, while preserving their activity (in terms of photocatalytic efficiency and hydrophobicity), were stable (meaning absence or, at least, delay of sedimentation, as observed in previous dispersions - Fig. S3 Supplementary material) or at any rate were easily redispersible. Many different trials were carried out to reach this purpose, by modifying several parameters $(\mathrm{pH}$, concentration of the photocatalysts, concentration of the superplasticizers).

Different strategies serve to the improvement of the coatings: 
i) $\mathrm{pH}$ modification, moving from slightly acidic dispersions (4.4 to 5.3) to an alkaline one, more compatible with some of the substrates, such as lime mortar and limestone. Changes towards a more alkaline medium also would enhance the performance of the superplasticizers, since many functional groups of these molecules are deprotonated under those $\mathrm{pH}$ conditions, allowing the anchorage of the active molecules and increasing their electrostatic repulsions (Plank, Sachsenhauser and de Reese 2010).

ii) concentration of the active photocatalyst: the use of larger amounts of the photocatalyst might render the coatings more efficient, although agglomeration of the nanoparticles together with a counter-effect due to the electron-hole recombination in case of an excess of photocatalyst will put a cap on the final admissible concentration.

iii) concentration of the superplasticizer: increasing amounts of the superplasticizer may result in an optimized dispersion of the nanoparticles.

Results showed the lowest sedimentation and segregation for the combinations of the superplasticizers melamine sulfonate (MEL) and polycarboxylate ether (PCE) with, respectively, $\mathrm{TiO}_{2}-\mathrm{ZnO} 10 / 90$ and 50/50 nanoparticles. As an example, the effect of the $\mathrm{pH}$ on the stability of the suspensions with increasing percentages of superplasticizer $(4,5,6$ and $7 \%)$ and with a constant $3 \%$ of the photocatalyst is shown in Fig. S4, Supplementary material. Dispersion at $\mathrm{pH} 9.5$ with $5 \%$ of PCE was selected as the optimum mixture to be applied (Dispersion 1). For $\mathrm{TiO}_{2}-\mathrm{ZnO} 10 / 90$ nanoparticles, the results showed that sample with $5 \%$ of MEL at the same $\mathrm{pH}$ of 9.5 was the most suitable (Dispersion 2).

Particle size distribution (Fig. 9a) of these optimized dispersions showed the clear improvement in the enhancement of the PSD, with a lower average particle diameter in comparison with samples in the absence of superplasticizer (depicted in Fig. 6). This finding is even more striking when considering that the concentration of the photocatalyst was now three times higher.

Zeta potential values were -12.5 and $-25.8 \mathrm{mV}$, respectively, for dispersions $\mathrm{TiO}_{2}-\mathrm{ZnO}$ $50 / 50$ with PCE and $\mathrm{TiO}_{2}$-ZnO 10/90 with MEL. The relatively low potential values suggest that the stability of the dispersions was due to the presence of the superplasticizers, containing functional groups (carboxylate and sulfonate) with a higher degree of deprotonation at the slight alkaline $\mathrm{pH}$ of the media.

Initial attempts of application of these coatings onto sandstone evidenced, however, some problems related to the whitening of the surfaces due to an apparent excess of photocatalyst (Fig. S5, Supplementary material). Measurements with CIELAB showed that in sandstone $\Delta \mathrm{E}^{*}$ of 6.20 (Dispersion 1) or 5.41 (Dispersion 2) (Table 4). 
To overcome this problem, assuming the right proportion between superplasticizer and photocatalyst, the two selected stock dispersions were then diluted, obtaining dispersions with $1.5 \%$ of nanoparticles and $2.5 \%$ of superplasticizer (PCE and $\mathrm{TiO}_{2}-\mathrm{ZnO}$ 50/50, Dispersion 3; MEL and $\mathrm{TiO}_{2}-\mathrm{ZnO} 10 / 90$, Dispersion 4). The application of these coatings yielded lower $\Delta E^{*}$ values (1.22 and 1.48) for both dispersions 3 and 4 applied onto sandstone, and the obtained values are below the perception threshold $\left(\Delta \mathrm{E}^{*}<3\right)$ according to the work by Pinho and Mosquera (2011) and satisfactory in the field of Cultural Heritage according to the work by Quagliarini et al. (2012).

This problem did not appear in the other substrates, with $\Delta \mathrm{E}^{*}$ values below 3 (Table 4) (Fig. S5, Supplementary material).

Table 4. $\Delta \mathrm{E}^{*}$ values after the application of the different coatings onto the substrates

\begin{tabular}{lccccc}
\hline & $\begin{array}{c}\text { Untreated } \\
\text { specimens }\end{array}$ & Dispersion 1 & Dispersion 2 & Dispersion 3 & Dispersion 4 \\
\hline Sandstone & & $6.20 \pm 0.71$ & $5.41 \pm 0.70$ & $1.22 \pm 0.52$ & $1.48 \pm 0.49$ \\
Lime mortar & & $0.61 \pm 0.37$ & $1.10 \pm 0.07$ & $1.41 \pm 0.36$ & $0.38 \pm 0.04$ \\
Granite & $0.21 \pm 0.57$ & $0.11 \pm 0.56$ & $0.15 \pm 0.78$ & $1.86 \pm 1.10$ \\
Limestone & $1.22 \pm 0.08$ & $1.12 \pm 0.01$ & $1.02 \pm 0.66$ & $1.29 \pm 0.29$ \\
\hline
\end{tabular}
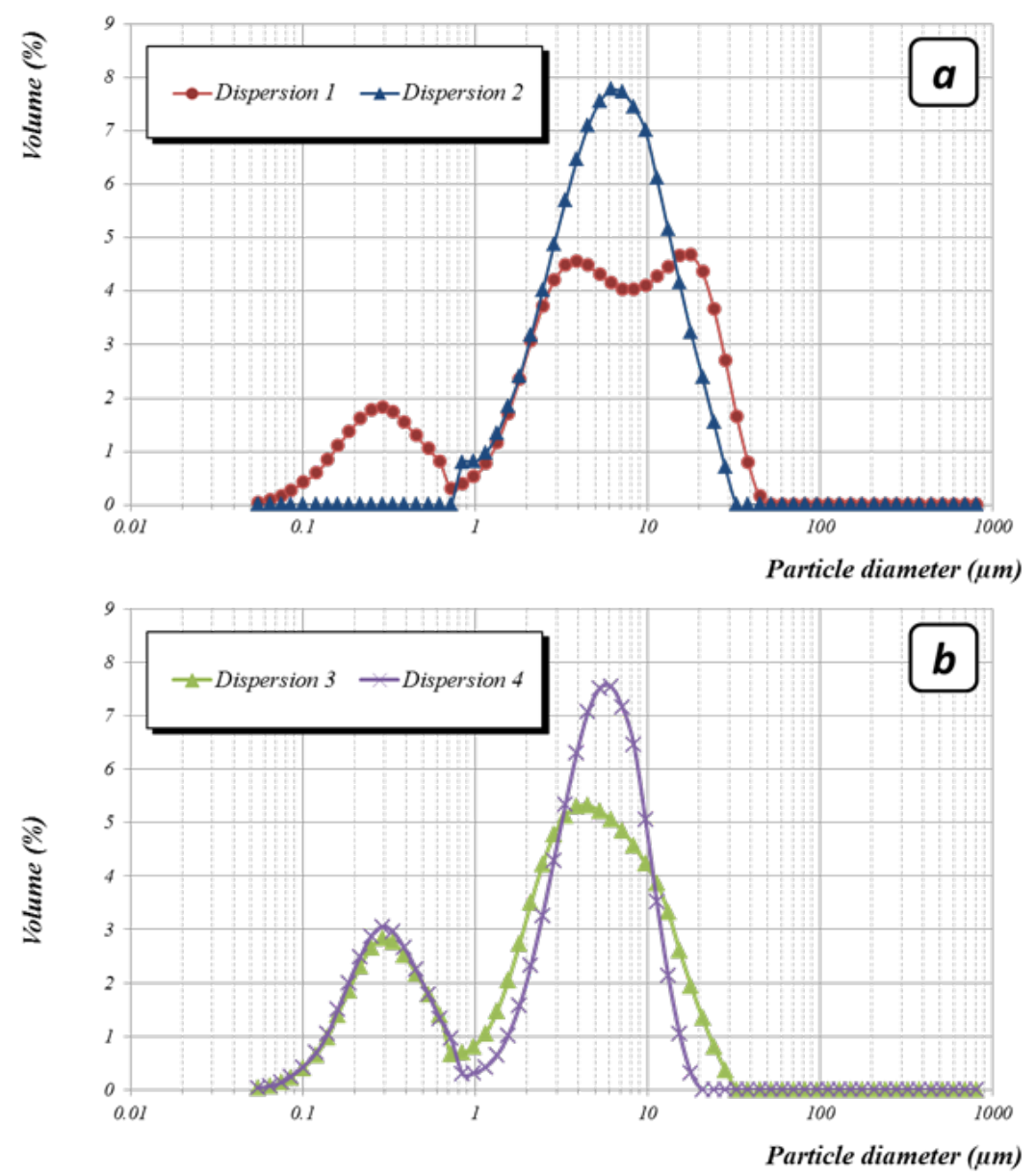

Figure 9. Particle size distribution of the nanoparticles in: a) Dispersion 1 and Dispersion 2. b) Dispersion 3 and Dispersion 4. 
These dilutions of the stock dispersions were also effective in order to reduce the particle size distribution of the nanoparticles, as can be inferred from the comparison between PSD curves depicted in Fig. 9b and in Fig. 9a. There are a lower number of big agglomerates of nanoparticles (larger than 10 microns) and an increased amount of population of the small sized particles (around 0.3 microns).

After confirming their stability and good dispersibility, the following four dispersions were used as coatings on the different substrates,:

- Dispersion 1: SPHB $3 \mathrm{w} / \mathrm{w} \% \mathrm{TiO}_{2}-\mathrm{ZnO} 50 / 50+5 \% \mathrm{w} / \mathrm{w}$ PCE with respect to the nanoparticles

- Dispersion 2: SPHB $3 \mathrm{w} / \mathrm{w} \% \mathrm{TiO}_{2}-\mathrm{ZnO} 10 / 90+5 \% \mathrm{w} / \mathrm{w}$ MEL with respect to the nanoparticles

- Dispersion 3: SPHB $1.5 \mathrm{w} / \mathrm{w} \% \mathrm{TiO}_{2}-\mathrm{ZnO} 50 / 50+2.5 \%$ w/w PCE with respect to the nanoparticles

- Dispersion 4: SPHB $1.5 \mathrm{w} / \mathrm{w} \% \mathrm{TiO}_{2}-\mathrm{ZnO} 10 / 90+2.5 \%$ w/w MEL with respect to the nanoparticles

\subsubsection{Performance of the optimized coatings}

Photocatalytic activity, as measured by the $\mathrm{NO}_{\mathrm{x}}$ abatement (Fig. 10a), showed that Dispersion 1 improved the $\mathrm{NO}_{\mathrm{x}}$ degradation as compared with non-optimized dispersions when applied onto sandstone, granite and limestone (NOx removal rates of 18.6, 15.1 and $14.7 \%$, respectively), whereas a reduction was observed for lime mortars. Dispersion 2, with MEL as superplasticizer, increased the $\mathrm{NO}_{\mathrm{x}}$ degradation for the comparatively less rough substrate, limestone, and for the smooth, granite, with, respectively, values of $10.9 \%$ and $12.0 \%$ of NOx removal, in front of the $6.2 \%$ and $5.8 \%$ measured for non-optimized dispersions..

Dispersion 3 (Fig. 10b) yielded very similar results to those of the dispersion 1 (with a slight improvement for the granite sample, with a $17.5 \%$ of NOx removal). Dispersion 4 yielded better $\mathrm{NO}_{x}$ abatement results in comparison with Dispersion 2, suggesting an enhanced activity (19.8\% of NOx removal for sandstone, $20.4 \%$ for granite and $23.6 \%$ for limestone). On average, percentages of $\mathrm{NO}_{\mathrm{x}}$ degradation increased 7.1. Dispersion 4 improved the results of the non-optimized dispersion for all the substrates except for lime mortars.

Dilution was positive for coatings with MEL as superplasticizer. A high percentage of this SP might be detrimental for the photocatalytic activity, since some of the active sites of the photocatalytic nanoparticles could be used to degrade the SP organic molecule. In addition, some electron-hole recombination for large amounts of photocatalyst have been described in the literature (Lucas, Ferreira and Barroso de Aguiar 2013), leading to a decrease in the activity. These facts account for the 
observed reduction in some cases. The roughness and porosity of the substrates seems to have strong influence. Conversely to the non-optimized coatings, these ones were seen to be more effective for substrates less porous and with scarce surface roughness: this was a favorable consequence of the superplasticizer, reducing the fast electron-hole recombination. For very porous substrates (e.g. air lime mortars, with a total porosity of $41.54 \%$ ), during the application, coating penetrates towards the inner part of the specimens. The access of the NO molecules to inner pores and intricate areas is thus hampered, explaining their lower efficiency.

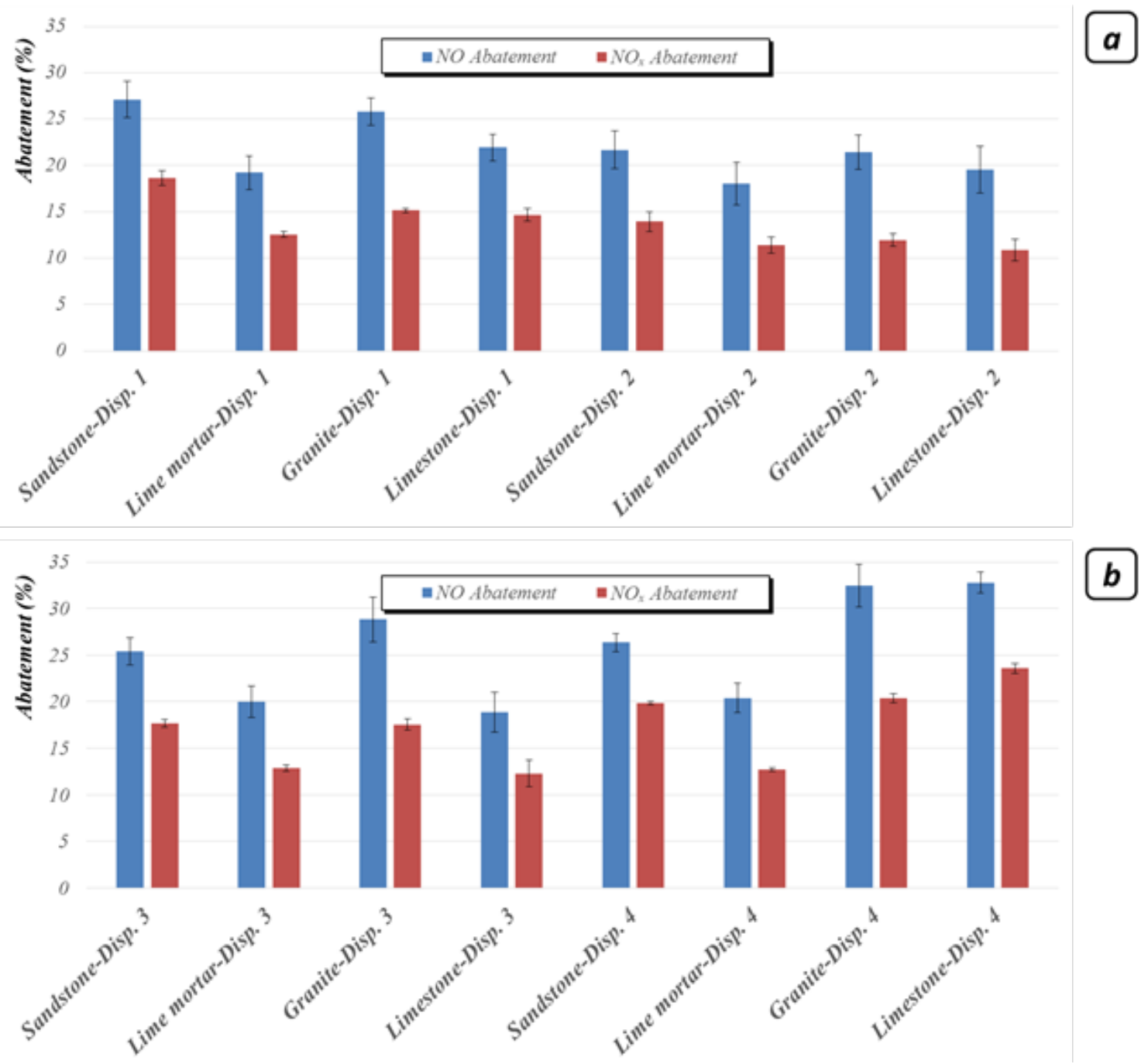

Figure 10. Effect of the different coatings on the nitrogen oxides degradation for granite as substrate (UV-vis radiation): a) Coatings 3\% of photocatalyst, $5 \%$ of SP with respect to the nanoparticles; b) Coatings $1.5 \%$ of photocatalyst, $2.5 \%$ of SP with respect to the nanoparticles.

Results of the hydrophobicity measured as water contact angle were gathered in Fig. 11. Just sample Lime mortar-Disp 4 yielded contact angles below $90^{\circ}$. This sample also yielded low $\mathrm{NO}_{x}$ degradation values, confirming the poor performance of this coating 
for this particular substrate. The other tested specimens with optimized coatings showed good photocatalytic activity combined with surface hydrophobicity.

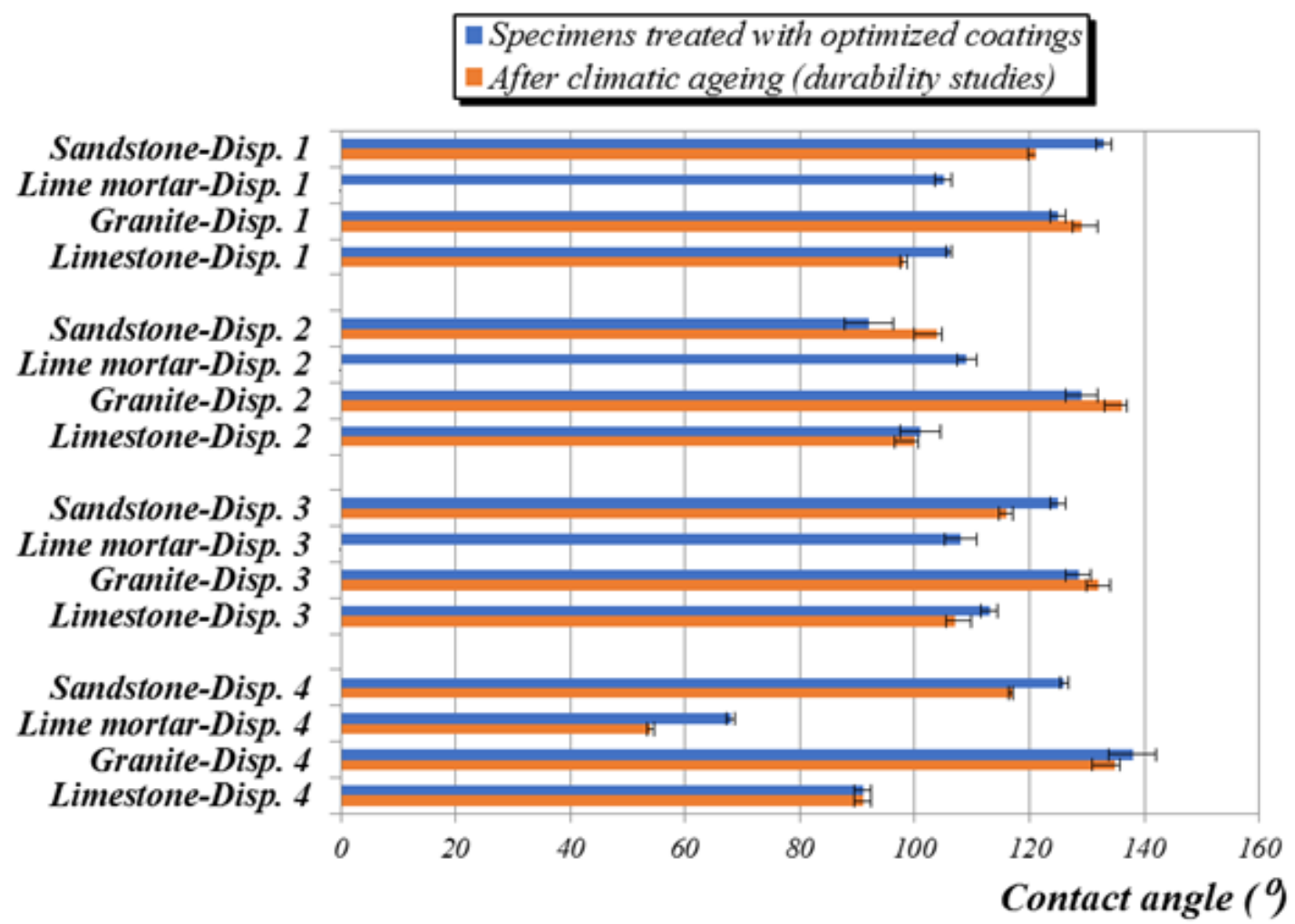

Figure 11. Static water contact angles for the different substrates with optimized coatings.

Self-cleaning assays were also conducted in order to assess the efficiency of these coatings. Fig. 12 shows the percentage of photodegradation of the colour $\left(\Delta \mathrm{E}^{*}\right)$ after the application of the stain of Rhodamine $\mathrm{B}$. The variation of $\Delta \mathrm{E}^{*}$ has been depicted in line with the work by Pinho and Mosquera (2011) and the percentage of discouloration has been calculated in a similar way to that reported by Quagliarini et al. (2012) for the coordinated $a^{*}$ of the CIELAB measurements.

For non-hydrophobic substrates, dye drop was partially absorbed and extended over the surface of the material immediately after the deposition. Samples with active coatings evidenced the self-cleaning ability monitoring the percentage of discouloration over the 48 hours after the dye deposition (24h and 48h) (Fig. 12). In comparison with untreated specimens, almost all coatings showed a higher discouloration after 24 and $48 \mathrm{~h}$ as well. The poorest performance was observed for lime mortar specimens with Dispersions 1 and 2 . This fact might be related to the porosity and roughness of the substrate,as well as to the failing in the coating application, as evidenced by the low $\mathrm{NO}_{\mathrm{x}}$ degradation values of these two samples. 

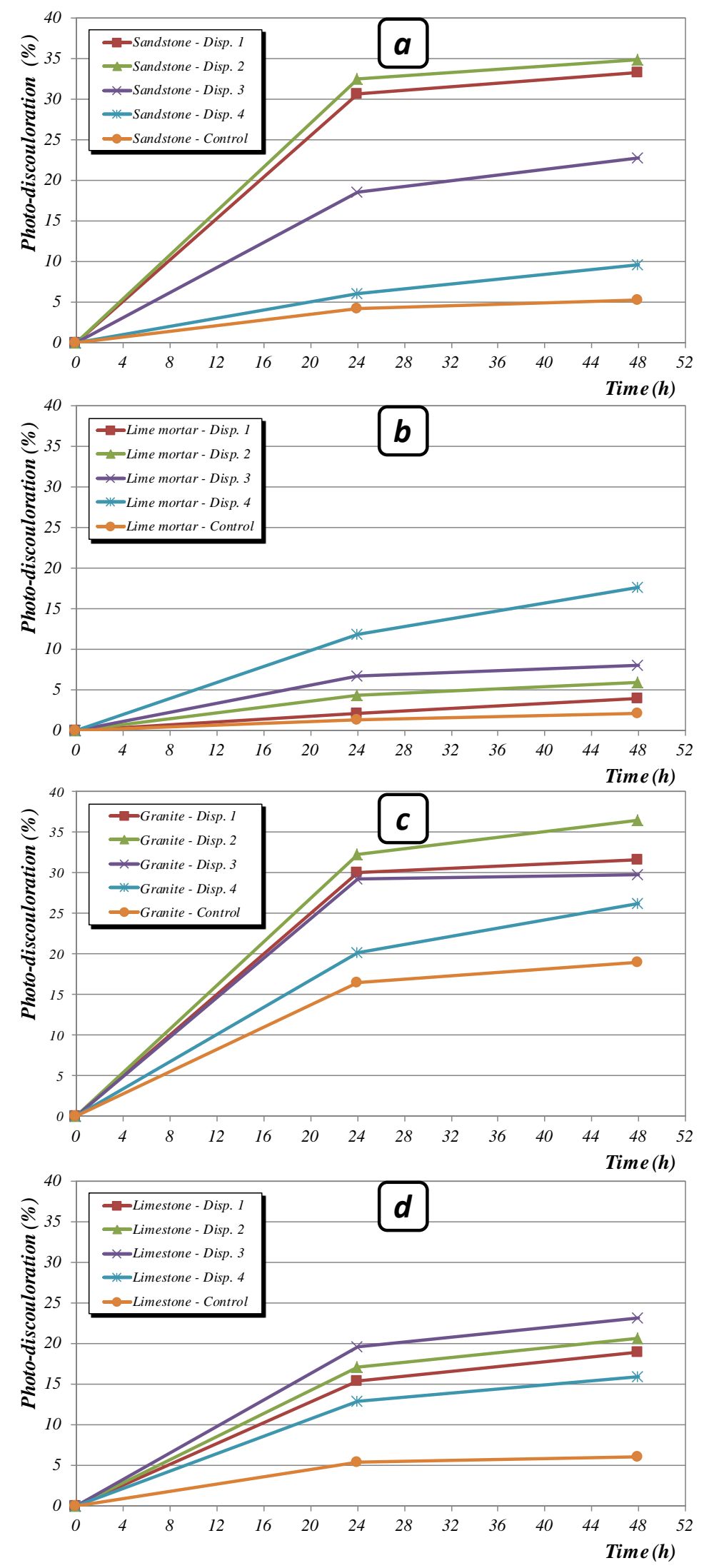

Figure 12. Percentage of photodegradation measured by discouloration (\% $\Delta \mathrm{E}^{*}$ reduction) after 24 and $48 \mathrm{~h}$ of the dye deposition (a: sandstone; b: lime mortar; c: granite; d: limestone). 
The increase in the percentages of discouloration of the stained surfaces due to the active coatings as compared with the untreated specimens ranged from $5-30 \%$ for sandstone, $2-16 \%$ for lime mortar, $7-17 \%$ for granite and $10-17 \%$ for limestone. Therefore, the self-cleaning ability of these coatings was confirmed.

Cleaning trials showed that the removal of the dye was very easy with water in the case of the specimens with active coatings, evidencing the effectiveness of the hydrophobic coating in preventing the formation of the bonds between the dye and the substrate.

The achievement of this synergistic effect between the photocatalyst agent (degrading the dye under illumination) and the hydrophobic component (avoiding the penetration and the bond formation between the dye (or the dirt) and the substrate) was the main challenge of the current work.

\subsubsection{Durability of the optimized coatings}

Coated specimens were subjected to accelerated climatic ageing with the aim of assessing the durability of the coating. Different weather conditions were simulated in a climatic chamber to reproduce real in-situ conditions. After the cycles, hydrophobicity and $\mathrm{NO}_{\mathrm{x}}$ abatement were monitored and compared with the results before the ageing. The degree of preservation of both properties, hydrophobicity and photocatalytic performance, was then used as indicator of the real applicability of these coatings.

Fig. 11 shows that the hydrophobicity of the specimens after the climatic ageing was well preserved for the majority of the specimens in comparison with the values before the durability test. Slight reductions in the WCA were observed for some substrates, whereas in some other cases very similar WCA were measured (increments are due to the roughness of the substrate, which induces variability during the recording of the experimental measurement). This finding means that optimized coatings were effective in preserving the water repellency of the treated surfaces even after harmful weather conditions.

Only lime mortars treated with dispersions 1, 2 and 3 showed non measurable WCA. This fact can be ascribed to the loss of the structural integrity of the substrate: given that the coating was applied only on the top surface, the other exposed areas of the lime mortar samples allowed the water entrance and the samples dissolution and disaggregation due to freezing-thawing phenomena. The brittle character of the lime mortar in comparison with the other three stony specimens explains the differences. As a consequence of the general decay of the lime mortar specimen, a significant part of the coating was lost, yielding thus a dramatic reduction in the water repellency. 
$\mathrm{NO}_{x}$ abatement of the samples subjected to weathering cycles was also measured and compared with the results before the durability studies (Fig. 13).
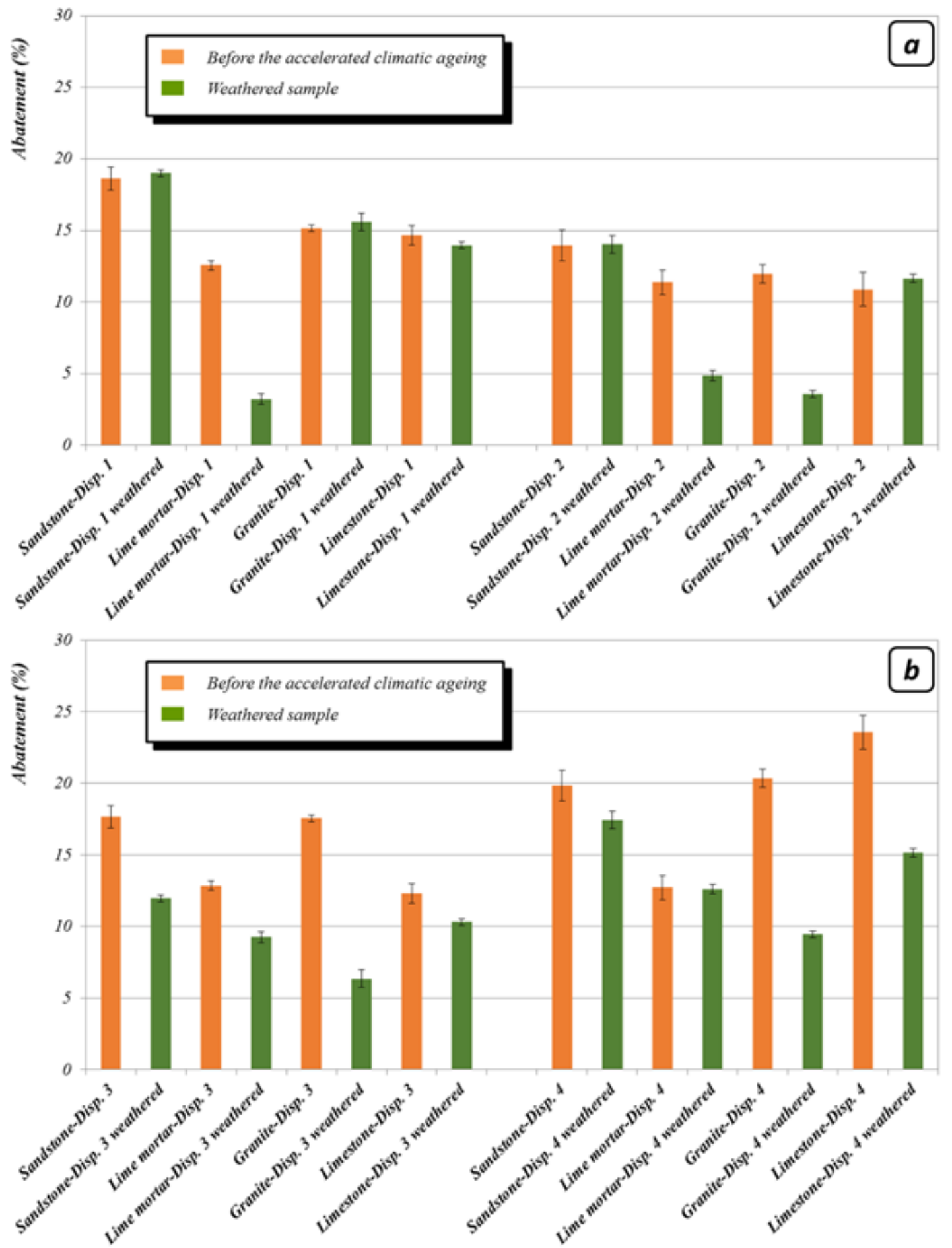

Figure 13. Comparison between $\mathrm{NO}_{\mathrm{x}}$ abatement results before and after (weathered samples) accelerated climatic ageing (UV-vis radiation)

Different behavior was observed depending on the applied coatings: Dispersion 1 was the most effective in preserving the photocatalytic effect after the accelerated climatic ageing. Within the experimental error, $\mathrm{NO}_{\mathrm{x}}$ abatement results were equal to those 
obtained for samples before the climatic ageing. Also Dispersion 2 was quite effective in whitstanding the weathering effect: significant reduction was observed only for granite substrates, and this fact could be related to the low roughness of this stony substrate, which difficults the coating adherence.

Lime mortars exhibited a different behavior since they were affected by the sharp loss of sample integrity, which had a strong influence on the $\mathrm{NO}_{\mathrm{x}}$ abatement results after the climatic ageing. For Dispersions 1 and 2, a dramatic $\mathrm{NO}_{\mathrm{x}}$ abatement reduction was observed, whereas Dispersion 3 yielded a moderated reduction and Dispersion 4 showed no changes.

The two dispersions with lower percentage of photocatalyst yielded more reduced values of activity in comparison with samples before ageing. The results of the Dispersion 3 showed a reduction in the $\mathrm{NO}_{\mathrm{x}}$ abatement values: for granite, again, the reduction was the highest. For sandstone, limestone and lime mortar, the photocatalytic efficiency was still relevant (see Fig. 13). The less efficient dispersion against climatic ageing was Dispersion 4, although for sandstone and limestone the photocatalytic effect yielded $\mathrm{NO}_{\mathrm{x}}$ abatement values higher than $15 \%$.

On the whole, the accelerated climatic ageing did not affect the water repellency of the treated stones (sandstone, granite and limestone), suggesting the long term durability of the hydrophobic properties. It is logical to expect a similar performance for lime mortars, subjected to further durability studies sealing the untreated areas to avoid catastrophic damages in the specimens.

Photocatalytic activity was also preserved for Dispersions 1 and 2 (both of them designed with the highest percentages of active nanoparticles), and particularly for rough substrates. However, the photocatalytic activity was affected for coatings with the lowest percentages of photocatalyst. Rough substrates, like sandstone and limestone, were able to keep a reasonable level of activity ( $\mathrm{NO}_{\mathrm{x}}$ abatement).

\section{Conclusions}

Multifunctional coatings combining a superhydrophobic inorganic 3D structure and active nanoparticles of $\mathrm{TiO}_{2}-\mathrm{ZnO} 50 / 50$ and 10/90 heterostructures have been obtained and applied onto inorganic substrates of the Built Heritage.

The synthesized nanoparticles were characterized and proved to be more photocatalytically active under solar light than raw $\mathrm{TiO}_{2}$ and $\mathrm{ZnO}$ materials. This finding was related to the reduction in the recombination of charge carriers, thanks to the heterojunction formed between the $\mathrm{CB}$ and $\mathrm{CV}$ bands.

The addition of the nanoparticles in SPHB medium and application on the stony substrates evidenced that the coatings imparted hydrophobicity - whereas allowed the 
breathability - to the treated surfaces, although photocatalytic efficiency underwent a reduction due to the agglomeration of the nanoparticles.

Dispersing agents (superplasticizers) were added to prevent nanoparticles from agglomeration thus improving the photocatalytic activity. Polycarboxylate-based and melamine sulfonate superplasticizers were found to be the most effective, although the stability of the dispersions was not adequate due to the sedimentation and segregation phenomena.

Optimization of the coatings was carried out to increase the stability of the dispersions, by modifying the $\mathrm{pH}$ as well as the percentages of the photocatalyst and superplasticizer too. Four dispersions were identified as the most suitable and the treated substrates showed that both hydrophobicity and photocatalytic activity were high.

- Dispersion 1: SPHB $3 \mathrm{w} / \mathrm{w} \% \mathrm{TiO}_{2}-\mathrm{ZnO} 50 / 50+5 \% \mathrm{w} / \mathrm{w}$ PCE with respect to the nanoparticles

- Dispersion 2: SPHB $3 \mathrm{w} / \mathrm{w} \% \mathrm{TiO}_{2}-\mathrm{ZnO} 10 / 90+5 \% \mathrm{w} / \mathrm{w}$ MEL with respect to the nanoparticles

- Dispersion 3: SPHB $1.5 \mathrm{w} / \mathrm{w} \% \mathrm{TiO}_{2}-\mathrm{ZnO} 50 / 50+2.5 \% \mathrm{w} / \mathrm{w}$ PCE with respect to the nanoparticles

- Dispersion 4: SPHB $1.5 \mathrm{w} / \mathrm{w} \% \mathrm{TiO}_{2}-\mathrm{ZnO} 10 / 90+2.5 \%$ w/w MEL with respect to the nanoparticles

Good self-cleaning ability (based on dye degradation) for the substrates treated with these dispersions was determined for the majority of the specimens.

Accelerated climatic ageing of the treated specimens showed that all the dispersions preserve hydrophobicity of the treated stones, whereas Dispersions 1 and 2, with the largest amount of photocatalyst, were most effective in preserving the photocatalytic activity.

The results of the current research work open a promising way of developing active multifunctional coatings with a good durability in the face of climatic weathering. Solar light-active nanoparticles will allow the application of these coatings in materials exposed to shadowed areas in which the UV photons are rather inaccessible. The SPHB medium was seen to be very effective and compatible with suitable amount of photocatalytic nanoparticles and dispersing agents. A wide range of materials of the Built Heritage could be treated with these coatings, which would impart water repellency and self-cleaning properties, avoiding the premature degradation of the materials, preserving the aesthetical appearance of the architectural monument and reducing the maintenance expenses.

\section{Acknowledgments}


This work was funded by Spanish Ministry of Economy and Competitiveness MINECO, Spain, under grant MAT2015-70728-P and by the Government of Navarra under grant number Exp. 0011-1383-2018-000005, project PC065 RECURBAN. J.F. González thanks the Friends of the University of Navarra, Inc., for a pre-doctoral grant.

\section{References}

Aldoasri, M.A., S.S. Darwish, M.A. Adam, N.A. Elmarzugi and S.M. Ahmed. 2017. Protecting of marble stone facades of historic buildings using multifunctional $\mathrm{TiO}_{2}$ nanocoatings. Sustainability 9 (11): 2002.

Alessandrini, G., M. Aglietto, V. Castelvetro, F. Ciardelli, R. Peruzzi and L. Toniolo. 2000. Comparative evaluation of fluorinated and un fluorinated acrylic copolymers as water-repellent coating materials for stone. Journal of Applied Polymer Science 76: 962-977.

Andreotti, S., E. Franzoni, M.D. Esposti and P. Fabbri. 2018. Poly(hydroxyalkanoate)s-based hydrophobic coatings for the protection of stone in cultural heritage. Materials 11: 165.

Aslanidou, D., I. Karapanagiotis and D. Lampakis. 2018. Waterborne superhydrophobic and superoleophobic coatings for the protection of marble and sandstone. Materials 11: 585.

Balbuena, J., M. Cruz-Yusta and L. Sánchez. 2015. Nanomaterials to combat $\mathrm{NO}_{\mathrm{x}}$ pollution. Journal of Nanoscience and Nanotechnology 15 (9): 6373-6385.

Bergamonti, L., I. Alfieri, A. Lorenzi, G. Predieri, G. Barone, G. Gemelli, P. Mazzoleni, S. Raneri, D. Bersani and P.P. Lottici. 2015. Nanocrystalline $\mathrm{TiO}_{2}$ coatings by sol-gel: photocatalytic activity on Pietra di Noto biocalcarenite. Journal of Sol-Gel Science and Technology 75: 141-151.

Bloh, J.Z., A. Folli and D.E. Macphee. 2014. Photocatalytic NOx abatement: why the selectivity matters. RSC Advances 4: 45726-45734.

Brai, M., M. Camaiti, C. Casieri, F. De Luca and P. Fantazzini. 2007. Nuclear magnetic resonance for cultural heritage. Magnetic Resonance Imaging 25 (4): 461465.

Brimblecombe, P. and C.M. Grossi. 2005. Aesthetic thresholds and blackening of stone buildings. Science of the Total Environment 349: 175-189.

Colangiuli, D., M. Lettieri, M. Masieri and A. Calia. 2019. Field study in an urban environment of simultaneous self-cleaning and hydrophobic nanosized $\mathrm{TiO}_{2}$-based 
coatings on stone for the protection of building surface. Science of the Total Environment 650: 2919-2930.

Conesa, J.C. 2012. Modeling with hybrid density functional theory the electronic band alignment at the zinc oxide-anatase interface. The Journal of Physical Chemistry C 116 (35): 18884-18890.

Doehne, E. and C.A. Price, eds. 2010. Stone conservation: an overview of current research. 2nd ed. Los Angeles, USA: Getty conservation Institute.

Du, Q., J. Ma, X. Shao, W. Wang and G. Tian. 2019. Core-shell structured $\mathrm{TiO}_{2} @ \mathrm{In}_{2} \mathrm{O}_{3}$ for highly active visible-light photocatalysis. Chemical Physics Letters 714: 208-212.

Duran, A., J.F. González-Sánchez, J.M. Fernández, R. Sirera, I. Navarro-Blasco, J.I. Alvarez. 2018. Influence of two polymer-based superplasticizers (Poly-naphthalene sulfonate, PNS, and lignosulfonate, LS) on compressive and flexural strength, freeze-thaw, and sulphate attack resistance of lime-metakaolin grouts. Polymers 10: 824 .

Fermo, P., G. Cappelletti, N. Cozzi, G. Padeletti, S. Kaciulis, M. Brucale and M. Merlini. 2014. Hydrophobizing coatings for cultural heritage. A detailed study of resin/stone surface interaction. Applied Physics A: Materials Science and Processing 116 (1): 341-348.

Fronzi, M., M.H.N. Assadi and D.A.H. Hanaor. 2019. Theoretical insights into the hydrophobicity of low index $\mathrm{CeO}_{2}$ surfaces. Applied science surface 478: 68-74.

Gobakis, K., D. Kolokotsa, N. Maravelaki-Kalaitzaki, V. Perdikatsis and M. Santamouris 2015. Development and analysis of advanced inorganic coatings for buildings and urban structures. Energy and Buildings 89: 196-205

Gomes, V., A. Dionísio, J.S. Pozo-Antonio, T. Rivas and A. Ramil. 2018. Mechanical and laser cleaning of spray graffiti paints on a granite subjected to a $\mathrm{SO}_{2}$-rich atmosphere. Construction and Building Materials 188: 621-632.

Gulotta, D., F. Villa, F. Cappitelli and L. Toniolo. 2018. Biofilm colonization of metamorphic lithotypes of a renaissance cathedral exposed to urban atmosphere. Science of the Total Environment 639: 1480-1490.

Guo, J., X. Liao, M.-H. Lee, G. Hyett, C.-C. Huang, D.W. Hewak, S. Mailis, W. Zhou and Z. Jiang. 2019. Experimental and DFT insights of the Zn-doping effects on the visible-light photocatalytic water splitting and dye decomposition over Zn-Doped $\mathrm{BiOBr}$ photocatalysts. Applied Catalysis B: Environmental 243: 502-512. 
Harbour, J.R., J. Tromp and M.L. Hair. 1985. Photogeneration of hydrogen peroxide in aqueous $\mathrm{TiO}_{2}$ dispersions. Canadian Journal of Chemistry 63 (1): 204-208.

Henderson, M.A. 2011. A surface science perspective on $\mathrm{TiO}_{2}$ photocatalysis. Surface Science Reports 66 (6-7): 185-297.

Hernández, S., V. Cauda, A. Chiodoni, S. Dallorto, A. Sacco, D. Hidalgo, E. Celasco

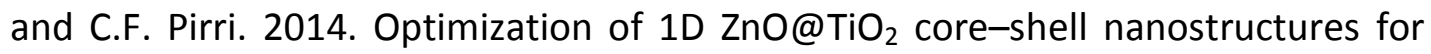
enhanced photoelectrochemical water splitting under solar light illumination. ACS Applied Materials \& Interfaces 6 (15): 12153-12167.

Hot, J., J. Topalov, R. Ringot and A. Bertron. 2017. Investigation on parameters affecting the effectiveness of photocatalytic functional coatings to degrade NO: $\mathrm{TiO}_{2}$ amount on surface, illumination, and substrate roughness. International Journal of Photoenergy 2017: 1-14.

ISO (International Organization for Standardization). 2016. ISO 22197-1:2016. Fine ceramics (advanced ceramics, advanced technical ceramics) - Test method for airpurification performance of semiconducting photocatalytic materials - Part 1: Removal of nitric oxide.

Kamegawa, T., K. Irikawa and H. Yamashita. 2015. Unique surface properties of nanocomposite thin film photocatalysts of $\mathrm{TiO}_{2}$ and Poly(tetrafluoroethylene). Chemistry Letters 44 (4): 509-511.

Kamegawa, T., Y. Shimizu and H. Yamashita, H. 2012. Superhydrophobic surfaces with photocatalytic self-Cleaning properties by nanocomposite coating of $\mathrm{TiO}_{2}$ and polytetrafluoroethylene. Advanced Materials 24: 3697-3700.

Kapridaki, C. and N.-P. Maravelaki. 2016. $\mathrm{TiO}_{2}-\mathrm{SiO}_{2}-\mathrm{PDMS}$ nanocomposites with self-cleaning properties for stone protection and consolidation. Geological Society London Special Publications 416 (1): 285-292.

Kapridaki, C. and P. Maravelaki-Kalaitzaki. 2013. $\mathrm{TiO}_{2}-\mathrm{SiO}_{2}-\mathrm{PDMS}$ nano-composite hydrophobic coating with self-cleaning properties for marble protection. Progress in Organic Coatings 76 (2-3): 400-410.

Kapridaki, C., L. Pinho, M.J. Mosquera and P. Maravelaki-Kalaitzaki. 2014. Producing photoactive, transparent and hydrophobic $\mathrm{SiO}_{2}$-crystalline $\mathrm{TiO}_{2}$ nanocomposites at ambient conditions with application as self-cleaning coatings. Applied Catalysis B: Environmental 156-157: 416-427.

Khalid, N.R., A. Majid, M. Bilal Tahir, N.A. Niaz and S. Khalid. 2017. Carbonaceous$\mathrm{TiO}_{2}$ nanomaterials for photocatalytic degradation of pollutants: A review. Ceramics International 43 (17): 14552-14571. 
Khan, M.M., S.A. Ansari, D. Pradhan, M.O. Ansari, D.H. Han, J. Lee and M.H. Cho. 2014. Modified $\mathrm{TiO}_{2}$ nanoparticles for visible light-induced photocatalytic activities. Journal of Materials Chemistry A 2: 637-644.

La Russa, M.F., S.A. Ruffolo, N. Rovella, C.M. Belfiore, A.M. Palermo, M.T. Guzzi and G.M. Crisci. 2012. Multifunctional $\mathrm{TiO}_{2}$ coatings for Cultural Heritage. Progress in Organic Coatings 74 (1): 186-191.

Lanka, S., E. Alexandrova, M. Kozhukhova, M., M.S. Hasan, M. Nosonovsky and K. Sobolev. 2019. Tribological and wetting properties of $\mathrm{TiO}_{2}$ based hydrophobic coatings for ceramics. Journal of Tribology 141 (10): 101301.

Lau, K.K.S., J. Bico, K.B.K. Teo, M. Chhowalla, G.A.J. Amaratunga, W.I. Milne, G.H. McKinley and K.K. Gleason. 2003. Superhydrophobic Carbon Nanotube Forests. Nano Letters 3 (12): 1701-1705.

Lee, C.-G., K.-H. Na, W.-T. Kim, D.-C. Park, W-H Yang and W-Y. Choi. 2019. $\mathrm{TiO}_{2} / \mathrm{ZnO}$ nanofibers prepared by electrospinning and their photocatalytic degradation of methylene blue compared with $\mathrm{TiO}_{2}$ nanofibers. Applied Sciences 9 (16): 3404.

Licciulli, A., A. Calia, M. Lettieri, D. Diso, M. Masieri, S. Franza, R. Amadelli and G. Casarano. 2011. Photocatalytic $\mathrm{TiO}_{2}$ coatings on limestone. Journal of Sol-Gel Science and Technology 60: 437-444.

Lipovsky, A., L. levitski, Z. Tzitrinovich, A. Gedanken and R. Lubart. 2012. The different behavior of rutile and anatase nanoparticles in forming oxy radicals upon illumination with visible light: an EPR study. Photochemistry and Photobiology 88: 14-20.

Liu, Q. and B.J. Zhang. 2007. Syntheses of a novel nanomaterial for conservation of historic stones inspired by nature. Materials Letters, 61 (28): 4976-4979.

Liu, X.Y., G. X. Chen and C.M. Su. 2011. Effects of material properties on sedimentation and aggregation of titanium dioxide nanoparticles of anatase and rutile in the aqueous phase. Journal of Colloid Interface Science 363: 84-91.

Liu, Y., T. Cai, L. Wang, S. Zhang, G. Zhang and X. Xia. 2017. Hollow microsphere $\mathrm{TiO}_{2} / \mathrm{ZnO} \mathrm{p}-\mathrm{n}$ heterojuction with high photocatalytic performance for 2,4Dinitropheno mineralization. Nano 12 (6): 1750076.

Low, J., J. Yu, M. Jaroniec, S. Wageh and A. Al-Ghamdi. 2017. Heterojunction photocatalysts. Advanced Materials 29: 101694.

Lucas, S.S., V.M. Ferreira and J.L. Barroso de Aguiar. 2013. Incorporation of titanium dioxide nanoparticles in mortars - Influence of microstructure in the 
hardened state properties and photocatalytic activity. Cement and Concrete Research 43: 112-120.

Macchia, A., S.A. Ruffolo, L. Rivaroli, M. Malagodi, M. Licchelli, N. Rovella, L Randazzo and M.F. La Russa. 2019. Comparative study of protective coatings for the conservation of Urban Art. Journal of Cultural Heritage. Advance online publication.

Manoudis, P.N., A. Tsakalof, I. Karapanagiotis, I. Zuburtikudis and C. Panayiotou. 2009. Fabrication of super-hydrophobic surfaces for enhanced stone protection. Surface and Coatings Technology 203 (10-11): 1322-1328.

Marcì, G., V. Augugliaro, M.J. López-Muñoz, C. Martín, L. Palmisano, V. Rives, M. Schiavello, R.J.D. Tilley and A.M. Venezia. 2001. Preparation characterization and photocatalytic activity of polycrystalline $\mathrm{ZnO} / \mathrm{TiO}_{2}$ systems. 2. Surface, bulk characterization, and 4-Nitrophenol photodegradation in liquid-solid regime. The Journal of Physical Chemistry B 105 (5): 1033-1040.

Mas, N., J.L. Hueso, G. Martinez, A. Madrid, R. Mallada, M.C. Ortega-Liebana, C. Bueno-Alejo and J. Santamaria. 2020. Laser-driven direct synthesis of carbon nanodots and application as sensitizers for visible-light photocatalysis. Carbon 156: 453-462.

Melo, M.J., S. Bracci, M. Camaiti, O. Chiantore and F. Piacenti. 1999. Phtodegradation of acrylic resins used in the conservation of stone. Polymer Degradation and Stability 66: 23-30.

Meseck, G.R., A. Käch and S. Seeger. 2014. Three-dimensional organization of surface-bound silicone nanofilaments revealed by focused ion beam Nanotomography. Journal of Physical Chemistry C 118: 24967-24975.

Nath, R.K., M.F.M. Zain and A.A.H. Kadhum. 2013. LiNbO3 coating on concrete surface: A new and environmentally friendly route for artificial photosynthesis. The Scientific World Journal 686497.

Navarro-Blasco, I., J.M. Fernández, A. Duran, R. Sirera and J.I. Álvarez. 2013. A novel use of calcium aluminate cements for recycling waste foundry sand (WFS). Construction and Building Materials 48: 218-228.

Pérez-Nicolás M., I. Navarro-Blasco, J.M. Fernández and J.I. Alvarez. 2017. Atmospheric NOx removal: study of cement mortars with iron- and vanadiumdoped $\mathrm{TiO}_{2}$ as visible light-sensitive photocatalysts. Construction and Building Materials 149: 257-271. 
Pérez-Nicolás, M., J. Plank, D. Ruiz-Izuriaga, I. Navarro-Blasco, J.M. Fernández and J.I. Alvarez. 2018. Photocatalytically active coatings for cement and air lime mortars: Enhancement of the activity by incorporation of superplasticizers. Construction and Building Materials 162: 628-648.

Pinho, L. and M.J. Mosquera. 2011. Titania-Silica nanocomposite photocatalysts with application in stone self-cleaning. Journal of Physical Chemistry C 115: 2285122862.

Piuzzi, E., E. Pittella, S. Pisa, A. Cataldo, E. De Benedetto and G. Cannazza. 2018. An improved noninvasive resonance method for water content characterization of Cultural Heritage stone materials. Measurement: Journal of the International Measurement Confederation 125: 257-261.

Plank, J., B. Sachsenhauser and J. de Reese. 2010. Experimental determination of the thermodynamic parameters affecting the adsorption behaviour and dispersion effectiveness of PCE superplasticizers. Cement and Concrete Research 40: 699-709.

Plank, J., D. Vlad, A. Brand, and P. Chatziagorastou. 2005. Colloidal chemistry examination of the steric effect of polycarboxylate superplasticizers. Cement International 3: 100-110.

Pozo-Antonio, J.S., I. Puente, M.F.C. Pereira and C.S.A. Rocha. 2019. Quantification and mapping of deterioration patterns on granite surfaces by means of mobile LiDAR data Measurement. Journal of the International Measurement Confederation 140: $227-236$.

Quagliarini, E., F. Bondioli, G.B. Goffredo, A. Licciulli and P. Munafò. 2012. Smart surfaces for architectural heritage: preliminary results about the application of $\mathrm{TiO}_{2}$-based coatings on travertine. Journal of Cultural Heritage 13: 204-209.

Sanmartín, P., F. Cappitelli and R. Mitchell, R. 2014. Current methods of graffiti removal: A review. Construction and Building Materials 71: 363-374.

Shajari-Ghasemkheili, S. and R. Sarraf-Mamoory. 2019. Development of a transparent silica-titania-methyl siliconate nanocoating with photocatalytichydrophobic properties aided by response surface method. Materials Research Express 6: 106430.

Speziale, A., J.F. González-Sánchez, I. Navarro-Blasco, J.M. Fernández and J.I. Álvarez. 2019. Active photocatalytic-superhydrophobic coating with $\mathrm{TiO}_{2}-\mathrm{ZnO}$ nano-heterostructures for lime mortars, in J.I. Alvarez, J.M. Fernández, Í. NavarroBlasco, A. Duran, R. Sirera (Editors) 5th Historic Mortars Conference. Book of Proceedings, RILEM Publications S.a.r.l., RILEM Proceedings PRO 130: 155-168. 
Šutka, A., M. Järvekülg and K.A. Gross. 2019. Photocatalytic nanoheterostructures and chemically bonded junctions made by solution-based approaches. Critical Reviews in Solid State and Materials Sciences 44 (3): 239-263.

Thakur, S., S. Maiti, S. Pal, S. and K.K. Chattopadhyay. 2018. Geometrically intricate oxide-based heterostructure over flexible platform: Morphology-induced catalytic performance enhancement under UV light. Lecture Notes in Electrical Engineering 462: 21-27.

Toniolo, L., T. Poli, V. Castelvetro, A. Manariti, O. Chiantore and M. Lazzari. 2002. Tailoring new fluorinated acrylic copolymers as protective coatings for marble. Journal of Cultural Heritage 3 (4): 309-316.

Tserepi, A.D., M.E Vlachopoulou and E. Gogolides. 2006. Nanotexturing of poly(dimethylsiloxane) in plasmas for creating robust super-hydrophobic surfaces. Nanotechnology 17 (15): 3977.

Turk, J., A.M. Pranjić, A. Hursthouse, R. Turner and J.J. Hughes. 2019. Decision support criteria and the development of a decision support tool for the selection of conservation materials for the built cultural heritage. Journal of Cultural Heritage 37: 44-53.

UNE-EN (Una Norma Española-European Norm) 1999. UNE-EN 1015-19:1999. Methods of test for mortar for masonry. Determination of water vapour permeability of hardened rendering and plastering mortars.

Ungan, H. and T. Tekin. 2019. Effect of the sonication and coating time on the photocatalytic degradation of $\mathrm{TiO}_{2}, \mathrm{TiO}_{2}-\mathrm{Ag}$, and $\mathrm{TiO}_{2}-\mathrm{ZnO}$ thin film photocatalysts. Chemical Engineering Communications. Advance online publication.

Veltri, S., A.M. Palermo, G. De Filpo and F. Xu. 2019. Subsurface treatment of $\mathrm{TiO}_{2}$ nanoparticles for limestone: Prolonged surface photocatalytic biocidal activities. Building and Environment 149: 655-661

Vidal, F., R. Vicente and J.M. Silva. 2019. Review of environmental and air pollution impacts on built heritage: 10 questions on corrosion and soiling effects for urban intervention. Journal of Cultural Heritage 37: 273-295.

Wang, D., P. Hou, L. Zhang, P. Yang and X. Cheng. 2017. Photocatalytic and hydrophobic activity of cement-based materials from benzyl-terminated- $\mathrm{TiO}_{2}$ spheres with core-shell structures. Construction and Building Materials 148: 176183. 
Wang, H., L. Zhang, Z. Chen, J. Hu, S. Li, Z. Wang, J. Liu, X. Wang. 2014. Semiconductor heterojunction photocatalysts: design, construction, and photocatalytic performances. Chemical Society Reviews 43: 5234-5244.

Winandy, L., O. Schlebusch and R. Fischer. 2019. Fungal hydrophobins render stones impermeable for water but keep them permeable for vapor. Scientific Reports 9 (1): 6264.

Wolfrum, E.J., J. Huang, D.M. Blake, P.-C. Maness, Z. Huang, J. Fiest and W.A. Jacoby. 2002. Photocatalytic oxidation of bacteria, bacterial and fungal spores, and model biofilm components to carbon dioxide on titanium dioxide-coated surfaces. Environmental Science \& Technology 36 (15): 3412-3419.

Yang, L., A. Hakki, F. Wang and D.E. Macphee. 2018. Photocatalyst efficiencies in concrete technology: The effect of photocatalyst placement. Applied Catalysis B: Environmental 222: 200-208,

Zhang, W.F., M.S. Zhang, Z. Yin and Q. Chen. 2000. Photoluminescence in anatase titanium dioxide nanocrystals. Applied Physics B 70 (2): 261-265.

Zhu, D. and Q. Zhou. 2019. Action and mechanism of semiconductor photocatalysis on degradation of organic pollutants in water treatment: A review. Environmental Nanotechnology, Monitoring \& Management 12: 100255.

Zhu, L., Z.-D. Meng, K.-Y. Cho, T. Ghosh and W.-C Oh. 2013. Enhancement of photocatalytic decolorization of methylene blue over $\mathrm{WO}_{3} / \mathrm{CNT}$ incorporated $\mathrm{TiO}_{2}$ nanocatalysts under UV light radiation. Asian Journal of Chemistry 25 (2): 713-718. 